\title{
The Expression and Prognostic Value of FGF2, FGFR3, and FGFBP1 in Esophageal Squamous Cell Carcinoma
}

\author{
Wenjing Zhang, ${ }^{1}$ Yaxing Zhou, ${ }^{1}$ Chao Li, ${ }^{2}$ Shanshan Xu, ${ }^{3}$ Mengyan Li, ${ }^{3}$ Wenying Liu, \\ Yuqing Ma $\left(1,{ }^{1}\right.$ and Hui Wang ${ }^{1}$ \\ ${ }^{1}$ Department of Pathology, First Affiliated Hospital, Xinjiang Medical University, Urumqi, Xinjiang, China \\ ${ }^{2}$ Department of RICU, First Affiliated Hospital, Xinjiang Medical University, Urumqi, Xinjiang, China \\ ${ }^{3}$ Department of Oncology, First Affiliated Hospital, Xinjiang Medical University, Urumqi, Xinjiang, China
}

Correspondence should be addressed to Yuqing Ma; yuqingm0928@126.com

Received 12 July 2020; Revised 30 October 2020; Accepted 12 November 2020; Published 11 December 2020

Academic Editor: Gian Luigi Mariottini

Copyright ( 2020 Wenjing Zhang et al. This is an open access article distributed under the Creative Commons Attribution License, which permits unrestricted use, distribution, and reproduction in any medium, provided the original work is properly cited.

\begin{abstract}
Background. Esophageal squamous cell carcinoma was treated by operation and chemoradiotherapy. However, the prognosis of most patients is poor after treatment, and most studies have shown that FGF2 and its receptor (FGFR) are involved in the development of various malignant tumors. FGF2 plays an important role in tumor progression and malignancy. In this study, the immunohistochemistry of FGF2, FGFR3, and FGFBP1 was used to further verify the expression of the three proteins in 172 patients with esophageal squamous cell carcinoma (ESCC) who had not received preoperative chemoradiotherapy and its effect on the prognosis of ESCC. Methods. (1) $\chi^{2}$ test was used to analyze the relationship between proteins and clinicopathological parameters. Survival analysis was used to investigate the effect of three proteins on prognosis. (2) Paired sample $t$-test was used to analyze the mRNA expression of the three proteins in fresh ESCC tissues and adjacent normal tissues. Results. FGF2 was correlated with tumor size $(p=0.026)$, gender $(p=0.047)$, and lymph metastasis $(p=0.007)$ in ESCC tissues. The high expression of FGFR3 was associated with tumor differentiation $(p=0.043$ and $p<0.05)$, lymph node metastasis $(p=0.078$ and $p<0.1)$, and race $(p=0.033$ and $p<0.05)$. The high expression of FGFBP1 was significantly associated with the degree of tumor differentiation $(p=0.012)$, age $(p=0.045)$, and lymph node metastasis $(p=0.032)$ of ESCC patients. The expression of FGF2, FGFR3, and FGFBP1-mRNA in ESCC tissues was significantly higher than that in adjacent tissues $(p<0.001, p<0.001$, and $p=0.001$ ). Patients with high expression of FGF2, FGFBP1, and FGFR3 had poor prognosis. There was a weak positive correlation between FGF2 and FGFBP1, as well as FGFR. Conclusion. The FGF2-FGFR3 axis may promote the progression of esophageal squamous cell carcinoma. The FGF2-FGFR3 axis may be a new direction of targeted therapy for esophageal squamous cell carcinoma. FGF2 and FGFR3 may be used as prognostic markers of esophageal squamous cell carcinoma.
\end{abstract}

\section{Introduction}

Esophageal cancer is a common digestive tract malignant tumor, which in sorted by histological type includes esophageal squamous cell carcinoma and esophageal adenocarcinoma. In European and American countries, the pattern is approximately $70 \%$ Barrett esophageal adenocarcinomas; while in China, the pattern is $95 \%$ esophageal squamous cell carcinoma [1], of which the 5-year survival rate is only $5 \%-$ $13 \%$ [2]. There are obvious regional and national differences in the distribution of esophageal cancer in China. The highincidence area of esophageal cancer is mainly distributed in the north China area, Dabie Mountain area, and between Fujian and Guangdong coastal area, and Xinjiang is also one of the high-risk areas [3]. The mechanism that occurs in the development of esophageal cancer is a complex combination with interactions at multistage, of multiple factors, and between multiple genes $[4,5]$. Treatment of esophageal cancer should be the use of surgery and chemoradiotherapy; however, due to the late detection of most patients, the prognosis is poor after treatment.

Growth factor fibroblast growth factor-2 (FGF2), also known as basic FGF [6], has been shown to exist in low molecular and high molecular weight isomers that are 
translated by a single common mRNA through another translation initiation codon [7]. Low molecular weight FGF2 is an $18 \mathrm{kDa}$ protein translated from the traditional AUG initiation codon. LMW FGF2, which exists in cytoplasm and nucleus, can also be secreted by the target cells. In order to start signal, the compound of LMW, FGF2, cell surface heparin sulfate proteoglycans (HSPGs), and fibroblast growth factor receptor (FGFR) activates downstream signaling pathways, including Ras, Raf, MAPK, and ERK [8]. The high molecular weight (HMW) FGF2 subtype is initiated by the translation of the upstream CUG locus and AUG codon frame. HMW FGF2 was located in the nucleus, and the signal was independent of FGFR [9]. The downstream signaling pathways are mediated by Ras/ERK and phosphoribosyl kinase (PI3K)/AKT signaling pathways in order to promote cell mitosis and regulate cell proliferation, differentiation, and migration [10]. FGF2 also plays an important role in tumor progression and malignancy, such as breast cancer and oral squamous cell carcinoma. FGF2, regulating CSCs through Mek/Erk signaling, is an important factor in esophageal squamous cell carcinoma [11].

FGFR, FGF2 receptors, is made of three Ig-like domains in the extracellular region, a single spanning transmembrane domain, and a split tyrosine kinase domain in the cytoplasmic region [12]. As FGF binds to FGFRs, the tyrosine kinase domain in the cytoplasmic region of the receptors is activated and generates signal paths, such as the Ras-MAPK, PI3KAKT, and PLC- $\gamma$-PKC pathways to induce cell proliferation, differentiation, migration, and tumor formation [13]. FGFR3 has carcinogenic activity in several cancers. The increased or mutated expression in FGFR3 leads to malignant progression in bladder cancer, colon cancer, and multiple myeloma [14-17].

FGFBP1 can bind to fibroblast growth factors such as FGF2, protect FGF2 from degradation, and present it to its high-affinity cell surface receptor, thus promoting the biological function of FGFs. FGFBP1 was reversibly combined with the acidic and basic fibroblast growth factor. FGF2 can closely bind HSPG in ECM and is only released through the action of FGFBP1 [18]. FGF binding protein is the key to FGF bioavailability regulatory factors [19]. Increasingly study has shown that FGFBP1 is highly expressed in skin cancer [20,21], but not clear in the mechanism of esophageal cancer.

The FGF/FGFR tyrosine kinase signal pathway regulates multiple biological events during embryogenesis and functions in the maintenance and repair of adult tissues [22]. This pathway is also implicated in both tumorigenesis and the development of chemoresistance in various types of cancers [23].

This study is designed to preliminarily analyze the expression of FGF2, FGFR3, FGFBP1, and their relationships with clinicopathological parameters in ESCC. The correlation among these proteins was analyzed through Spearman correlation analysis. Furthermore, we investigated to evaluate the effect of FGF2, FGFR3, and FGFBP1 on the prognosis of ESCC through Kaplan-Meier analysis. Our findings suggested that the FGF2-FGFR3 axis may be a new direction of targeted therapy for ESCC.

\section{Materials and Methods}

From January 2014 to June 2018, 172 cases of esophageal squamous cell carcinoma (including 94 cases of Han nationality and 78 cases of Hazak nationality) were collected from the First Affiliated Hospital of Xinjiang Medical University, including their clinicopathological data: age $(<65$ and $\geq 65)$, gender (male and female), nationality, location (upper, middle, and lower), tumor size $(<3 \mathrm{~cm}$ and $\geq 3 \mathrm{~cm})$, differentiation degree (high differentiation, middle differentiation, and low differentiation), lymph node metastasis (yes and no), vascular infiltration (yes and no), nerve infiltration (yes and no); distant metastasis (yes and no), pTNM stage (the eighth edition) (IB, IIA $+\mathrm{B}$, and IIIA $+\mathrm{B}+\mathrm{C})$, and treatment (surgery and postoperative chemoradiotherapy) (Table 1). None of the selected patients completed neoadjuvant therapy preoperatively. All the selected patients were patients with advanced esophageal squamous cell carcinoma without early cancer (T1N0M0). All the selected patients underwent radical resection of esophageal carcinoma and lymph node dissection. According to $2020 \mathrm{CSCO}$ esophagus cancer diagnosis and treatment guidelines, the patients of $\mathrm{cT} 1 \mathrm{~b} \mathrm{cT} 2 \mathrm{~N}+$ or cT3cT4a, any $\mathrm{N}$ needs to be radical surgery and at the same time chemoradiotherapy. All the selected patients in this study required postoperative chemoradiotherapy. And the study was approved by Ethical Committee of the First Affiliated Hospital of Xinjiang Medical University. Our follow-up time ended in July 2019 through inquiring the medical records and telephone calls.

2.1. Immunohistochemistry. (1) Anti-FGFR3 (product no. BM5016), anti-FGF2 antibody (EP1735) (ab92337), and anti-FGFBP1 antibody (ab238155) were used as the reagents

(2) Methods: with SP method, 172 cases of embedded esophageal cancer, paraffin tissue, and normal mucosal tissue were made into tissue chips, which were made into $4 \mathrm{mic}$ continuous sections. The tissues were surgical samples. After dewaxing and dehydration, the tissue chips were put into a boiling repair solution, citric acid (PH6.0), heated to $95^{\circ} \mathrm{C}$, and kept them in the acid for 20 minutes. After 30-minute cooling at room temperature, these chips were added into endogenous peroxidase and incubated for 20 minutes in the room temperature. The tissue chips were washed in phosphate-buffered saline for three-times (3 min/time). After that, anti-FGFR3 (BM5016) $\left(1: 50,4^{\circ} \mathrm{C}\right.$ overnight), antiFGFBP1 antibody (ab238155) $\left(1: 800,4^{\circ} \mathrm{C}\right.$ overnight), and anti-FGF2 antibody (EP1735) (ab92337) $\left(1: 800,4^{\circ} \mathrm{C}\right.$ overnight) were dipped onto these chips separately. When the time is up, the chips were washed in phosphate buffer saline (PBS) for three times, were dropped with goat anti-mouse secondary antibody (PV-6002, Zsbio, Beijing, China), and were placed in an oven at $37^{\circ} \mathrm{C}$ for 40 minutes. Finally, the slides were dyed in prepared $\mathrm{DAB}$ solution, redyed with hematoxylin, dehydrated with graded alcohol, covered with slide, and installed for review.

(3) The staining intensity score of FGFBP1 was 0 (negative), 1 (weak), and 2 (strong). The dyeing range is based on the percentage of positive tumor cell score of 0 (negative), 1 (1\% and $25 \%), 2$ (26\% and 50\%), 3 (51\% and $75 \%)$, or 4 
TABLE 1: Clinicopathological characteristics of esophageal squamous cell carcinoma patients $(n(\%))$.

\begin{tabular}{|c|c|}
\hline Characteristics and finding & $n=172$ \\
\hline Age (years old) & $63.53(38-83)$ \\
\hline Tumor size $(\mathrm{cm})$ & $3.81(1-8.5)$ \\
\hline \multicolumn{2}{|l|}{ Gender } \\
\hline Male & $129(75)$ \\
\hline Female & $43(25)$ \\
\hline \multicolumn{2}{|l|}{ Race } \\
\hline Han & $94(54.7)$ \\
\hline Kazak & $78(45.3)$ \\
\hline \multicolumn{2}{|l|}{ Tumor site } \\
\hline Upper & $8(4.7)$ \\
\hline Middle & $95(55.2)$ \\
\hline Lower & $69(40.1)$ \\
\hline \multicolumn{2}{|l|}{ Differentiation } \\
\hline Well & $33(19.2)$ \\
\hline Moderate & $97(56.4)$ \\
\hline Poor & $42(24.4)$ \\
\hline \multicolumn{2}{|l|}{ pTNM } \\
\hline IB & $12(7)$ \\
\hline IIA,B & $86(50)$ \\
\hline IIIA,B,C & $74(43)$ \\
\hline \multicolumn{2}{|l|}{ Lymph metastasis } \\
\hline Negative & $113(65.7)$ \\
\hline Positive & $59(34.3)$ \\
\hline \multicolumn{2}{|l|}{ Vessel invasion } \\
\hline Negative & $141(82)$ \\
\hline Positive & $31(18)$ \\
\hline \multicolumn{2}{|l|}{ Nerve invasion } \\
\hline Negative & $136(79.1)$ \\
\hline Positive & $36(20.9)$ \\
\hline \multicolumn{2}{|l|}{ Distant metastases } \\
\hline Negative & $132(76.7)$ \\
\hline Positive & $40(23.3)$ \\
\hline \multicolumn{2}{|l|}{ Treatment } \\
\hline Surgery & $109(63.4)$ \\
\hline Postoperative chemoradiotherapy & $63(36.6)$ \\
\hline \multicolumn{2}{|l|}{ FGF2 } \\
\hline Low expression & $55(32)$ \\
\hline High expression & $117(68)$ \\
\hline \multicolumn{2}{|l|}{ FGFR3 } \\
\hline Low expression & $61(35.5)$ \\
\hline High expression & $111(64.5)$ \\
\hline \multicolumn{2}{|l|}{ FGFBP1 } \\
\hline Low expression & $60(34.9)$ \\
\hline High expression & $112(65.1)$ \\
\hline
\end{tabular}

(76\% and $100 \%)$. The final score is the product of the staining intensity score and the staining range score. If the final score is 0 to $4( \pm)$, the case is ultimately considered negative. If the
TABLE 2: PCR primer sequences.

\begin{tabular}{lcc}
\hline Gene name & & \multicolumn{2}{c}{ Sequence } \\
\hline \multirow{2}{*}{ FGF2 } & $\begin{array}{l}\text { Forward } \\
\text { Reverse }\end{array}$ & $\begin{array}{c}\text { TTCAAGCAGAAGAGAGAGGAG } \\
\text { TCCGTAACACATTTAGAAGCC }\end{array}$ \\
\hline \multirow{2}{*}{ FGFR3 } & Forward & ACCAAGCCTGTCACCGTAG \\
& Reverse & CAGAAACTCCCGCAGGTTACC \\
\hline \multirow{2}{*}{ FGFBP1 } & Forward & GGGAGGAGCTGTGAGTAACG \\
& Reverse & CAGGCAGTGCGAGTGAATTG \\
\hline
\end{tabular}

final score is $5(+)$ to $8(+++)$, the final score is positive. Expression levels of FGF2 and FGFR3 were assessed by semiquantitative scoring, including percentage of total lesion area (0-100\%) and staining intensity (0-3). The expression of epithelium, endothelial cells, and stroma was analyzed in all cases. The classification of area positive rate is as follows: $<10 \%=0,10-25 \%=1,25-50 \%=2,50-75 \%=3$, and $>75 \%=4$. To assess intensity, the grades were as follows: 0: none; 1: mild; 2: moderate; and 3: strong staining. The percentage score $(0-4)$ was multiplied by the intensity score (0-3), and the final score was assigned with 0-4 for negative staining and 5-12 for positive staining [24]

2.2. qRT-PCR. (1) Extraction of total RNA: firstly, 29 cases of esophageal cancer and their paired adjacent normal tissues were taken out from the refrigerator at $-80^{\circ} \mathrm{C}$. Secondly, the liquid nitrogen was added to them for milling, and Trizol reagent was also added to extract the total RNA in the tissues after grinding according to the instructions. Thirdly, the concentration of total RNA in the extracted tissues was measured by NanoDrop 2000c uv spectrophotometer. After the electrophoresis test, cDNA was transcribed. According to the instructions of the reverse transcription kit, 2 ng taken from the total RNA extracted was added into the reverse transcription reaction system under the following conditions: $25^{\circ} \mathrm{C}$ $5 \mathrm{~min}, 42^{\circ} \mathrm{C} 60 \mathrm{~min}, 70^{\circ} \mathrm{C} 5 \mathrm{~min}$, and $4^{\circ} \mathrm{C}$ forever. The synthesized $\mathrm{CDNA}$ was stored in a refrigerator at $-80^{\circ} \mathrm{C}$ for later use. The primer sequences are listed in Table 2.

(2) qRT-PCR use a two-step method with SYBR Green (Applied Biosystems 7500, Thermo Fisher Scientific)

(3) The above reaction elements were added into the reaction system, and the reaction conditions were as follows: predenaturation at $95^{\circ} \mathrm{C}$ for $2 \mathrm{~min}$, denaturation at $95^{\circ} \mathrm{C}$ for $10 \mathrm{~s}$, annealing at $60^{\circ} \mathrm{C}$ for $10 \mathrm{~s}$, extension at $72^{\circ} \mathrm{C}$ for $5 \mathrm{~min}$, and 40 cycles in total. Each sample was repeated at least 3 times, with 3 multiple holes set for each time (Table 2)

2.3. Statistical Analysis. SPSS 25.0 statistical software was used. $\chi^{2}$ test and Fisher exact test were used to analyze the relationship between clinicopathological characteristics and the expression of FGF2, FGFR3, and FGFBP1 in esophageal squamous cell carcinoma. The correlation between FGF2, FGFR3, and FGFBP1 was also analyzed by Spearman grade correlation. Use overall survival and progression-free survival to estimate survival time. Progression-free survival is 


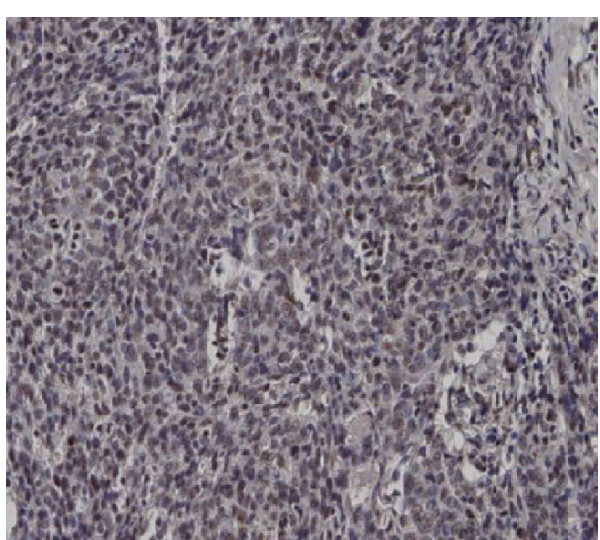

(a)

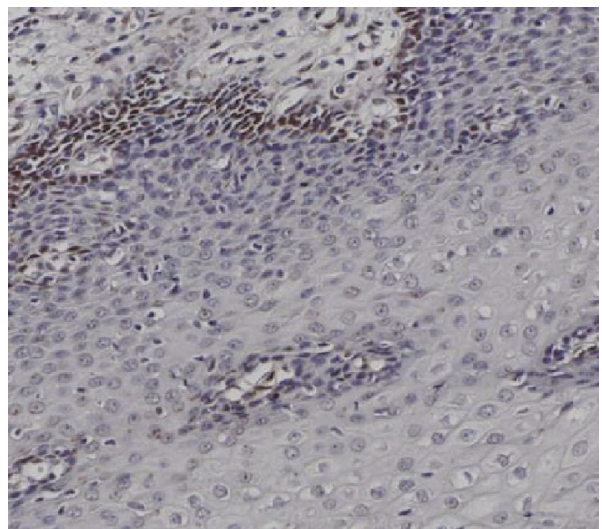

(c)

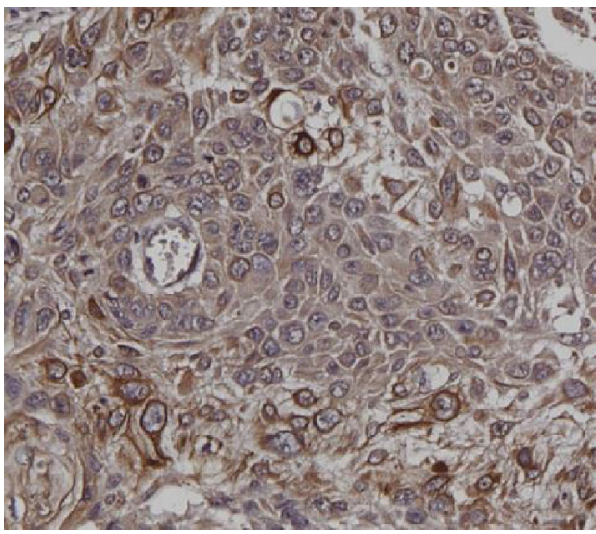

(e)

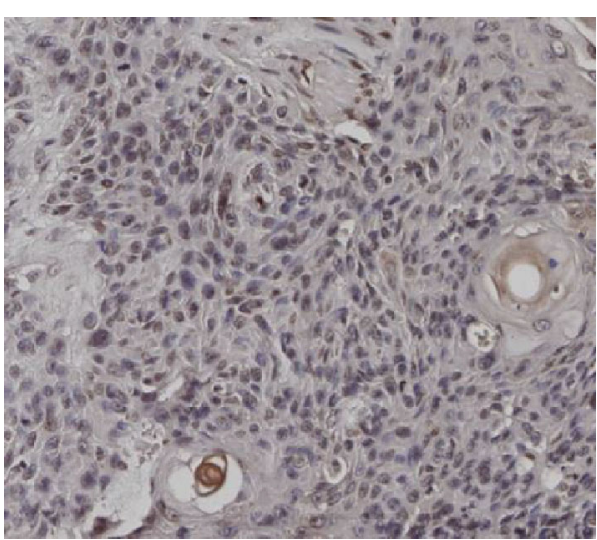

(b)

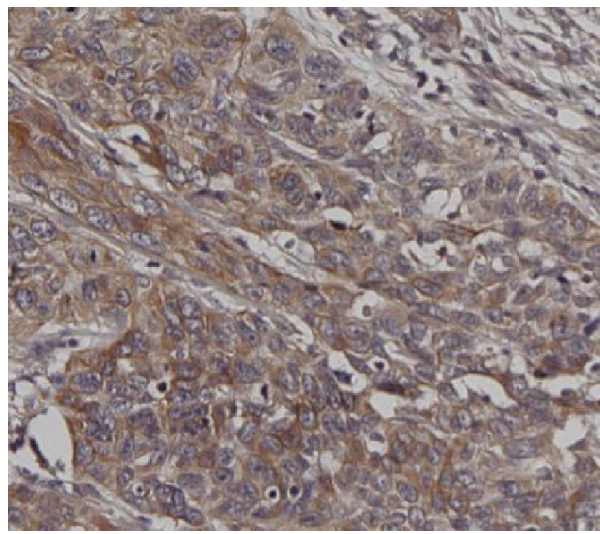

(d)

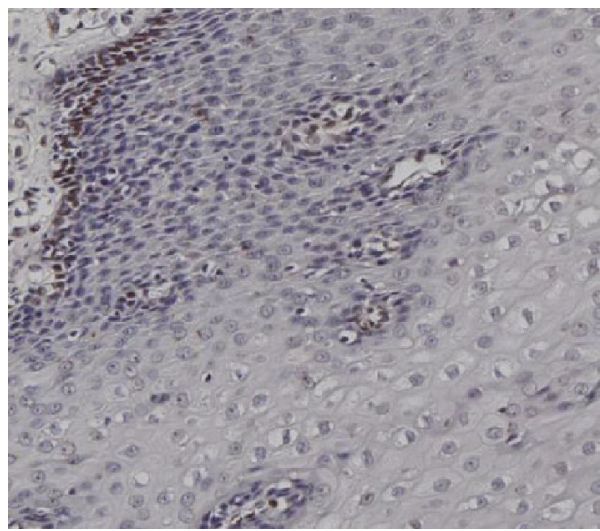

(f)

Figure 1: Continued. 


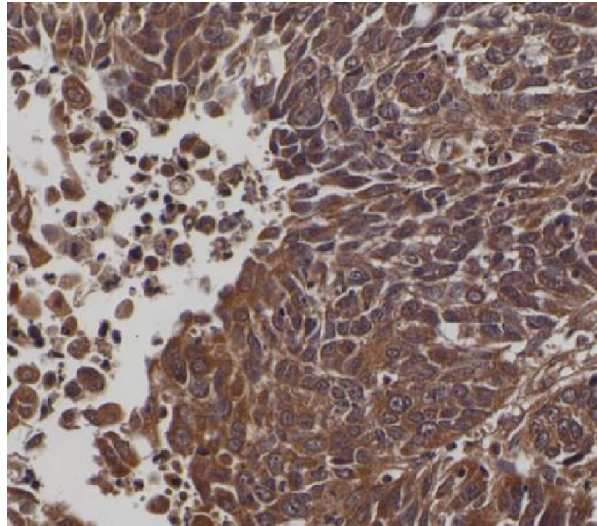

(g)

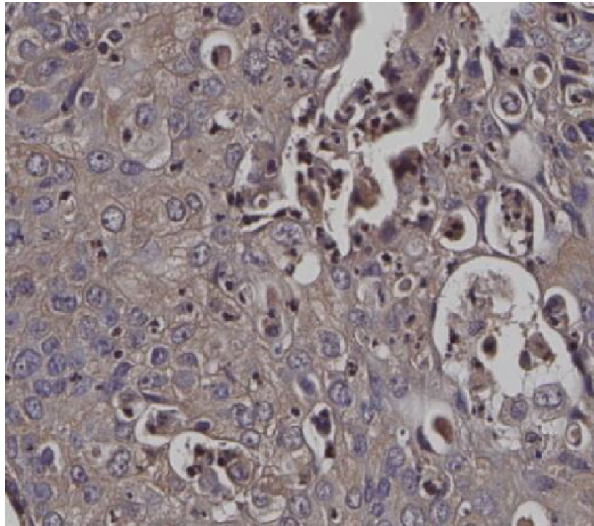

(h)

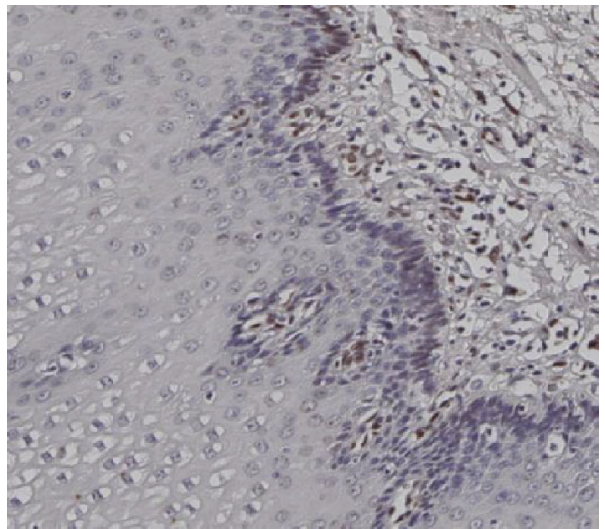

(i)

FIGURE 1: Immunohistochemical staining of FGF2, FGFR3, FGFBP1 expression in ESCC and normal esophagus mucosa. (a, b) Positive expression of FGF2 in ESCC tumor tissue; (c) positive expression of FGF2 in the basal layer of normal esophageal mucosa; (d, e) positive expression of FGFR3 in ESCC tumor tissue; (f) positive expression of FGFR3 in the basal layer of normal esophageal mucosa; $(\mathrm{g}, \mathrm{h})$ positive expression of FGFBP1 in ESCC tumor tissue; (i) negative expression of FGFBP1 in normal esophageal mucosa.

defined as the diagnosis of esophageal squamous cell carcinoma of the time to tumor progression or death. Overall survival is defined as the diagnosis of esophageal cancer patients with time to death or final follow-up time (2019-07-01). The effects of FGF2, FGFR3, FGFBP1 protein, and clinicopathological parameters on the prognosis of ESCC were analyzed by Kaplan-Meier method. Based on Kaplan-Meier analysis results, independent factors related to the prognosis of esophageal squamous cell carcinoma were further analyzed by Cox proportional risk model. The method was forward LR, and $p<0.05$ was considered significant. For qRT-PCR results, the ct value of the cancerous tissue and the ct value of the adjacent tissues were used to calculate the 2- $\Delta \Delta \mathrm{ct}$ value. If the two groups of values accord with normal distribution and homogeneity of variance, the paired sample $t$-test is adopted. If the measured data are nonnormal and homogeneity of variance, the nonparametric Wilcoxon rank sum test is adopted.

\section{Results and Analysis}

3.1. The Expression of FGF2, FGFR3, and FGFBP1 in ESCC and Their Relationship with Clinicopathological Parameters. The expression of FGF2 in ESCC is shown in the figure (Figures 1(a)-1(c)). FGF2 was positive in the nucleus and cytoplasm of ESCC, negative in normal esophageal mucosa, or positive only in basal cells. In this study, there were 172 patients with esophageal squamous cell carcinoma, of which 55 (32\%) were FGF2 negative and 117 (68\%) were FGF2 positive. Statistical analysis showed that high expression of FGF2 was correlated with tumor size $(p=0.026)$, gender $(p=0.047)$, and lymph metastasis $(p=0.007)$. The expression of FGF2 was not correlated with race $(p=0.794)$, age $(p=0.053)$, tumor site $(p=0.902)$, differentiation $(p=0.231)$, and pathological stage of ESCC cases $(p=0.325)(p>0.05)$ and so on (Table 3).

The expression of FGFR3 in ESCC and its relationship with clinicopathological parameters was investigated. As is shown in Figures 1(d)-1(f), positive FGFR3 staining signals were brown and yellow, located in the cytoplasm and membrane of the esophageal cancer cells. In normal tissues adjacent to cancer, FGFR3 positive signals were found in the basal layer of esophageal mucosa. All tumor specimens were divided into the FGFR3-low expression group (61 cases, 35.5\%) and the FGFR3-high expression group (111 cases, $64.5 \%)$. As is shown in Table 3 summary, the correlation is 
TABLE 3: Relationship between expression of FGF2, FGFR3, and FGFBP1 in ESCC and clinicopathological parameters ( $n$ ).

\begin{tabular}{|c|c|c|c|c|c|c|c|c|c|c|}
\hline \multirow{2}{*}{ Characteristic } & \multirow{2}{*}{$\begin{array}{c}\text { Total } \\
n=172\end{array}$} & \multicolumn{2}{|c|}{ FGF2 expression $n$} & \multirow{2}{*}{$p$} & \multicolumn{2}{|c|}{ FGFR3 expression $n$} & \multicolumn{4}{|c|}{ FGFBP1 expression } \\
\hline & & Negative & Positive & & Negative & Positive & & Negative & Positive & \\
\hline Gender & & & & 0.047 & & & 0.519 & & & 0.712 \\
\hline Male & 129 & 36 & 93 & & 44 & 85 & & 46 & 83 & \\
\hline Female & 43 & 19 & 24 & & 17 & 26 & & 14 & 29 & \\
\hline Race & & & & 0.794 & & & 0.033 & & & 0.302 \\
\hline Han & 94 & 31 & 63 & & 40 & 54 & & 24 & 54 & \\
\hline Hazak & 78 & 24 & 54 & & 21 & 57 & & 36 & 58 & \\
\hline Age (years) & & & & 0.053 & & & 0.384 & & & 0.045 \\
\hline$<65$ & 91 & 35 & 56 & & 35 & 56 & & 38 & 53 & \\
\hline$\geq 65$ & 81 & 20 & 61 & & 26 & 55 & & 22 & 59 & \\
\hline Tumor size & & & & 0.026 & & & 0.885 & & & 0.811 \\
\hline$<3 \mathrm{~cm}$ & 44 & 20 & 24 & & 16 & 28 & & 16 & 28 & \\
\hline$\geq 3 \mathrm{~cm}$ & 128 & 35 & 93 & & 45 & 83 & & 44 & 84 & \\
\hline Tumor site & & & & 0.902 & & & 0.548 & & & 0.457 \\
\hline Upper & 8 & 3 & 5 & & 4 & 4 & & 4 & 4 & \\
\hline Middle & 95 & 31 & 64 & & 35 & 60 & & 35 & 60 & \\
\hline Lower & 69 & 21 & 48 & & 22 & 47 & & 21 & 48 & \\
\hline Differentiation & & & & 0.231 & & & 0.043 & & & 0.012 \\
\hline Well & 33 & 11 & 22 & & 12 & 21 & & 15 & 18 & \\
\hline Moderate & 97 & 35 & 62 & & 43 & 54 & & 41 & 56 & \\
\hline Poor & 42 & 9 & 33 & & 6 & 36 & & 4 & 38 & \\
\hline Pathological stage & & & & 0.325 & & & 0.897 & & & 0.320 \\
\hline IB & 12 & 6 & 6 & & 5 & 7 & & 6 & 6 & \\
\hline IIA,B & 86 & 28 & 58 & & 30 & 56 & & 32 & 54 & \\
\hline IIIA,B,C & 74 & 21 & 53 & & 26 & 48 & & 22 & 52 & \\
\hline Lymph metastasis & & & & 0.007 & & & 0.078 & & & 0.032 \\
\hline Negative & 113 & 44 & 69 & & 45 & 68 & & 45 & 68 & \\
\hline Positive & 59 & 11 & 48 & & 16 & 43 & & 15 & 48 & \\
\hline Vascular invasion & & & & 0.644 & & & 0.68 & & & 0.735 \\
\hline Negative & 141 & 44 & 97 & & 51 & 90 & & 50 & 91 & \\
\hline Positive & 31 & 11 & 20 & & 10 & 21 & & 10 & 21 & \\
\hline Nerve invasion & & & & 0.313 & & & 0.764 & & & 0.826 \\
\hline Negative & 136 & 46 & 90 & & 49 & 87 & & 48 & 88 & \\
\hline Positive & 36 & 9 & 27 & & 12 & 24 & & 12 & 24 & \\
\hline Distant metastases & & & & 0.142 & & & 0.494 & & & 0.718 \\
\hline Negative & 132 & 46 & 86 & & 45 & 87 & & 47 & 85 & \\
\hline Positive & 40 & 9 & 31 & & 16 & 24 & & 13 & 27 & \\
\hline
\end{tabular}

between FGFR3 expression and clinicopathological features. Statistical analysis showed that overexpression of FGFR3 expression was correlated with tumor differentiation $(p=0.043$ and $p<0.05)$, lymph node metastasis $(p=0.078$ and $p<0.1)$, and race $(p=0.033$ and $p<0.05)$.

The expression of FGFBP1 in ESCC is shown in Figures 1(g)-1(i). The positive signal of FGFBP1 is mainly located in the cytoplasm and membrane of the esophageal cancer cells and is positively expressed in the normal esophageal mucosal epithelium. Statistical analysis showed that the high expression of FGFBP1 was significantly cor- related with the degree of tumor differentiation $(p=0.012)$, age $(p=0.045)$, and lymph node metastasis $(p=0.032)$ of ESCC patients, while no association was significantly correlated for high expression of FGFBP1 with gender $(p=0.559)$, race $(p=0.302)$, tumor size $(p=0.267)$, tumor site $(p=0.457)$, pathological stage $(p=0.320)$, vascular invasion $(p=0.735)$, and so on $(p>0.05)$ (Table 3$)$.

3.2. Correlation of FGF2, FGFR3, and FGFBP1 Protein Expression. Spearman level correlation analysis was performed in 172 cases of esophageal squamous cell carcinoma, 
and the protein expression of FGF2 was significantly correlated with FGFR3 and FGFBP1 $(p<0.001$, rs $=0.612 ; p<$ 0.001 , rs $=0.649)$. FGFR3 and FGFBP1 were further analyzed and found that there is a positive correlation $(p<0.001$, rs $=0.656$ ), as is shown in Tables 4 and 5. These three proteins are highly expressed in esophageal squamous cell carcinoma. According to their correlation, it was speculated that the FGF2-FGFR3 axis formed by FGF2, FGFR3, and FGFBP1 may promote ESCC progression.

3.3. $q R T-P C R$. The results showed that mRNA expressions of FGF2 $(p<0.001)$, FGFR3 $(p<0.001)$, and FGFBP1 $(p=0.001)$ were higher in cancer tissues than in the adjacent tissues $(p<0.05)$ (Figure 2$)$. The difference was statistically significant. The results were consistent with the immunohistochemical results.

3.4. Prognostic Factors for OS and PFS. Kaplan-Meier method was used to investigate the relationship between protein expression level and survival rate. Four were lost to follow-up in the 172 patients. Through K-M single-factor analysis, the overall survival rate was closely correlated with FGF2 $(p<0.001)$, FGFBP1 $(p<0.001)$, FGFR3 expression $(p<0.001)$, lymph node metastasis $(p=0.006)$, vascular invasion $(p=0.011)$, nerve invasion $(p=0.02)$, and the treatment with postoperative chemoradiotherapy $(p=0.002)$ (Figures 3 and 4). However, there was no obvious relation, with sex, tumor size, degree of differentiation, and TNM. And progression-free survival is closely related to FGF2 $(p<0.001)$, FGFR3 $(p<0.001)$, and FGFBP1 $(p<0.001)$; lymph node metastasis $(p=0.005)$; vascular invasion $(p=$ $0.008)$, and distant metastases $(p=0.008)$, as is shown in Figure 5 and Table 6 . The progression-free survival of FGF2-, FGFR3-, and FGFBP1-positive patients was significantly lower than that of negative patients. Cox multivariate regression analysis showed that, as is shown in Table 6, vascular invasion $(p=0.03)$ and postoperative chemotherapy $(p=0.001)$ can significantly have an impact on the overall survival status of ESCC patients (Table 6). FGF2 $(p<0.001)$, FGFR3 $(p=0.003)$, vascular invasion $(p=0.033)$ and distant metastases $(p=0.014)$ can significantly have an influence on the progression-free survival status of patients (Table 6).

To sum up, we analyze the impact of various factors on the overall survival and progression-free survival. Patients with vascular metastases have a worse prognosis. Postoperative chemotherapy patients have a better prognosis than those who only underwent surgery. Patients with distant metastasis have a worse prognosis. The survival time of patients with lymph node metastasis was significantly lower than that of patients without lymph node metastasis. The overall survival of FGF2-, FGFR3-, and FGFBP1-positive patients is significantly lower than that of negative patients. For the patients with low expression of FGF2, FGFR3, and FGFBP1 are longer than that of patients with high expression in progression-free survival.

3.5. The Expression of FGF2, FGFR3, FGFBP1 Effect Overall Survival and Progression-Free Survival Time in Patients with Postoperative Chemotherapy. In our study, there are 51
TABLE 4: Correlation between FGF2 and FGFR3 and FGFBP1.

\begin{tabular}{ccccc}
\hline & \multicolumn{2}{c}{ FGF2 } & $p$ & rs \\
\hline FGFR3 & Positive & Negative & & \\
Positive & $99(57.5 \%)$ & $12(7 \%)$ & $<0.001$ & 0.612 \\
Negative & $18(10.5 \%)$ & $43(25 \%)$ & & \\
FGFBP1 & & & & \\
Positive & $101(58.7 \%)$ & $11(6.4 \%)$ & $<0.001$ & 0.649 \\
Negative & $16(9.3 \%)$ & $44(25.6 \%)$ & & \\
\hline
\end{tabular}

TABLE 5: Correlation between FGFR3 and FGFBP1.

\begin{tabular}{ccccc}
\hline & \multicolumn{2}{c}{ FGFR3 } & \multirow{2}{*}{$p$} & rs \\
\hline FGFBP1 & Positive & Negative & & \\
Positive & $98(57 \%)$ & $14(8.1 \%)$ & $<0.001$ & 0.656 \\
Negative & $13(7.6 \%)$ & $47(27.3 \%)$ & & \\
\hline
\end{tabular}

patients $(30.3 \%)$ underwent postoperative chemotherapy. $33(64.7 \%)$ cases had high expression of FGF2, and 18 $(35.3 \%)$ cases had negative expression. There were 32 positive cases of FGFR3 and 19 negative cases, with a positive rate of $62.7 \%$. There were 30 cases $(58.8 \%)$ who had high expression of FGFBP1 and $21(41.2 \%)$ cases who had negative expression, as is shown in Table 7 and Figure 6. The results showed that patients with ESCC receiving postoperative chemoradiotherapy had longer survival time, but these patients with high expression of FGF2 $(p=0.05)$, FGFR3 $(p=0.025)$, and FGFBP1 $(p=0.005)$ had significantly lower overall survival than those with negative expression. In progression-free survival, patients with high expression of FGF2 $(p<0.001)$, FGFR3 $(p<0.001)$, and FGFBP1 $(p<0.001)$ had significantly lower survival than those with low expression.

\section{Discussion}

Fibroblast growth factor (FGF) represents 20 different proteins that are widely expressed in various tissues. Fibroblast growth factor (FGF) is involved in biological development and tissue homeostasis maintenance and is associated with angiogenesis and cancer progression [25]. FGF2 (basic FGF) is one of the most thoroughly studied members of the FGF family and has been shown to play a variety of biological roles in different cell and organ systems. It has also been shown to be involved in tumorigenesis and angiogenesis [13]. FGF2 in the tumor microenvironment plays a key role in regulating cancer stem-like cells (CSCs) [26], promoting the occurrence and development of tumors. In fibrosarcoma, cancer cells and their surrounding immune inflammatory cells overexpress or induce FGF2 expression, which plays a key role in tumor progression and angiogenesis [27]. In breast cancer cells, FGF2 showed high expression and was a 
(b1)

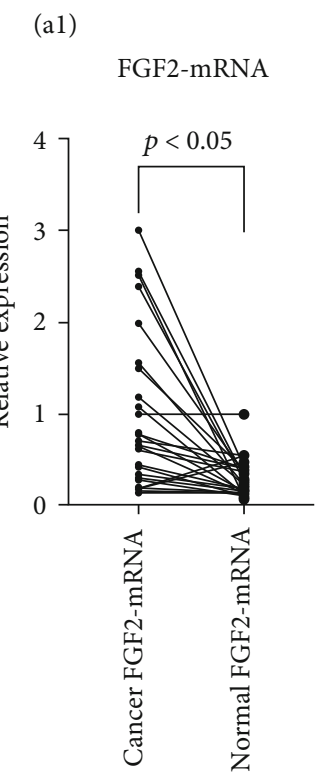

(a2)

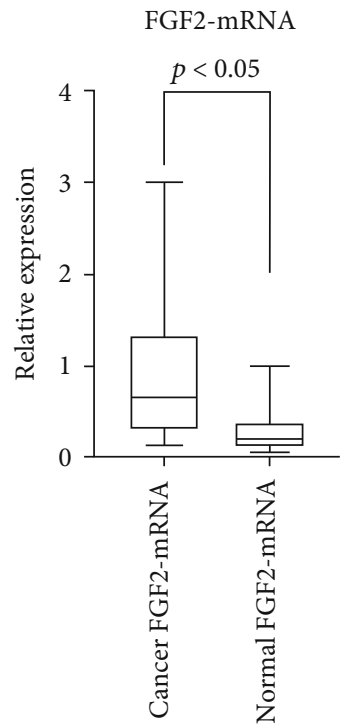

(a)

(c1)

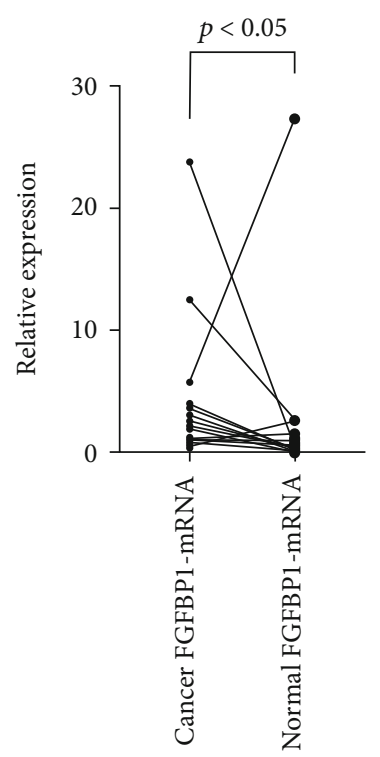

FGFR3-mRNA
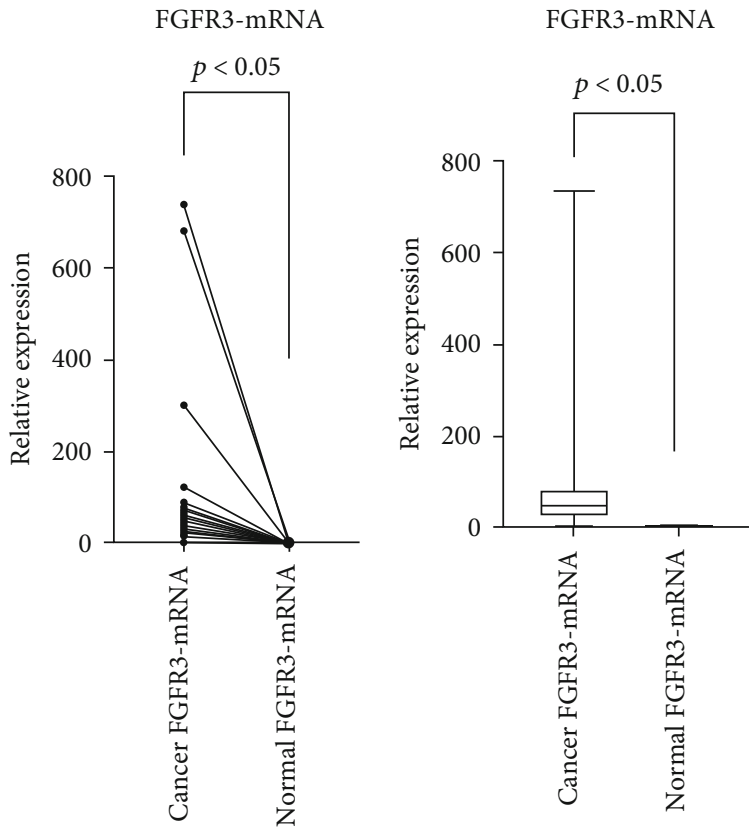

(b)

(c2)

FGFR3-mRNA (b2)

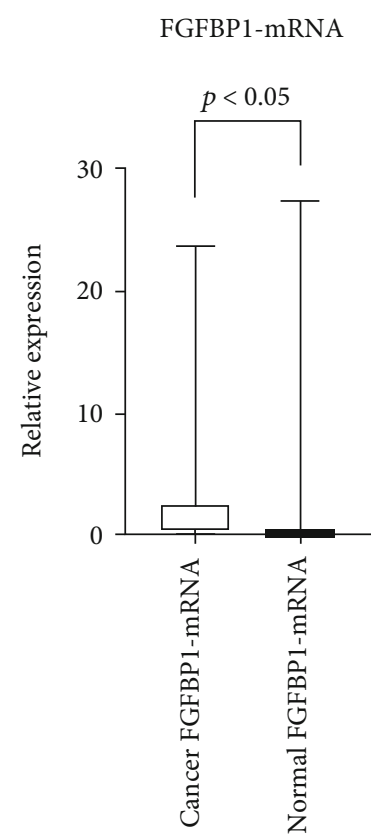

(c)

FIGURE 2: The expression of FGF2, FGFR3, and FGFBP1-mRNA in cancer tissues was significantly higher than that in adjacent tissues $(p<0.05)$.

powerful mitogen and an effective antiapoptotic substance, while inducing its invasion $[28,29]$. Takase et al. analyzed the tissue specimens of 70 cases of esophageal squamous cell carcinoma by immunohistochemistry to investigate whether the expression level of FGF2 is related to the clinicopathological parameters of ESCC patients. According to the expression level of FGF2, they were further classified into weak positive group and strong positive group. The results showed that the strong positive group was positively correlated with the depth of infiltration, degree of vascular infiltration, and stage [30]. The results of our study showed that the expression of ESCC patients was significantly higher than that of normal esophageal tissues, and the positive rate was $68 \%(117 / 172)$, which was 


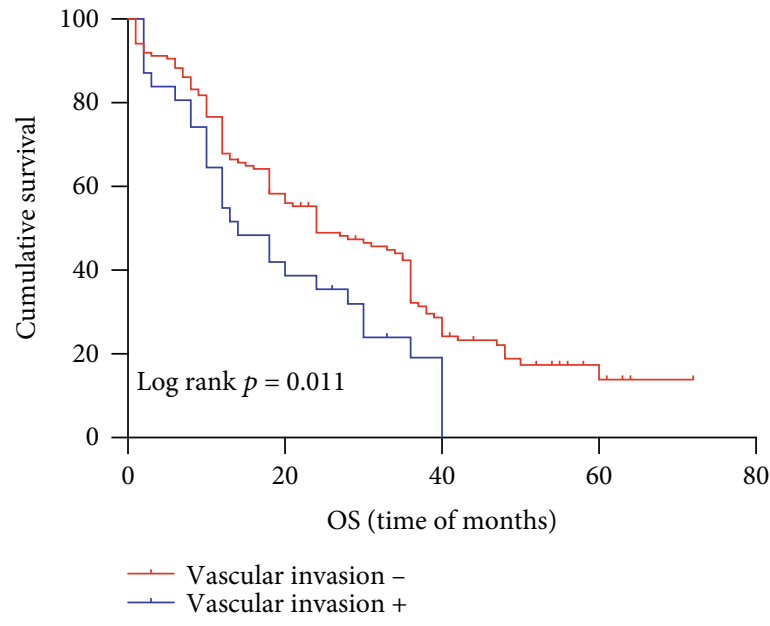

(a)

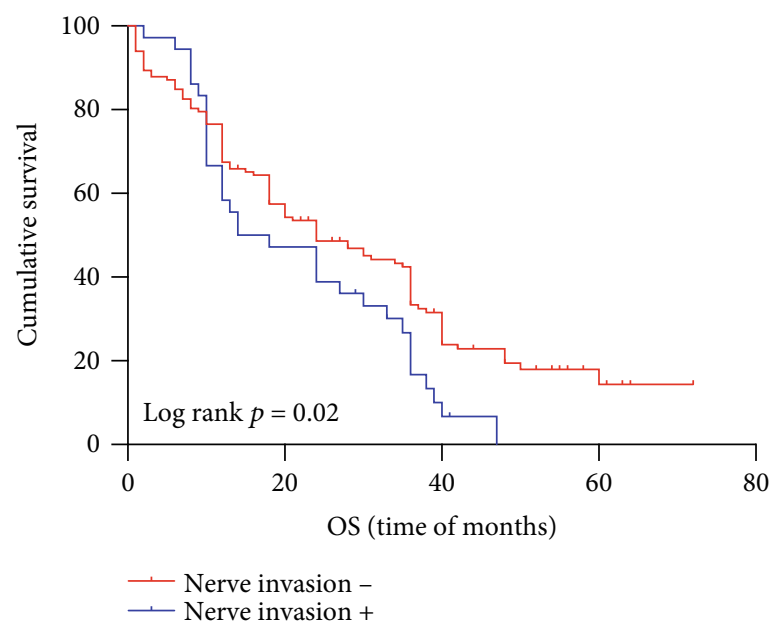

(c)

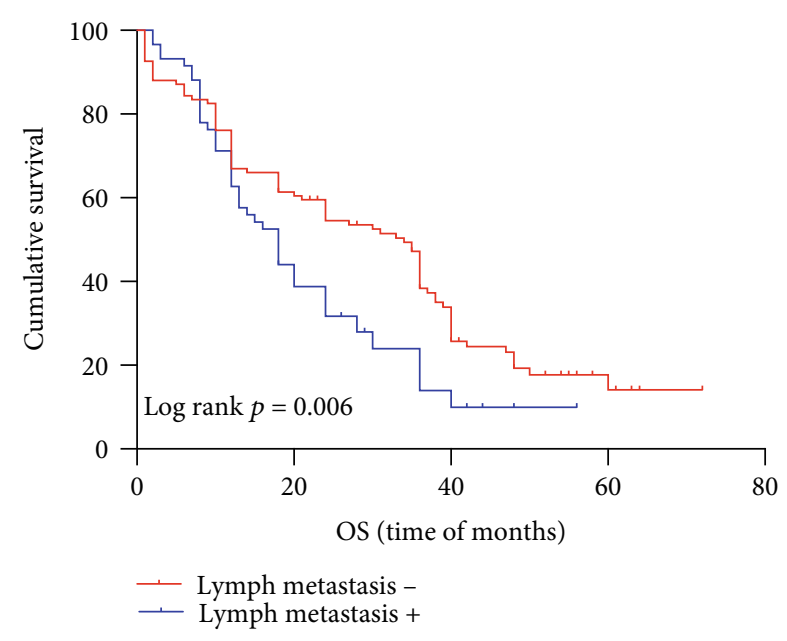

(b)

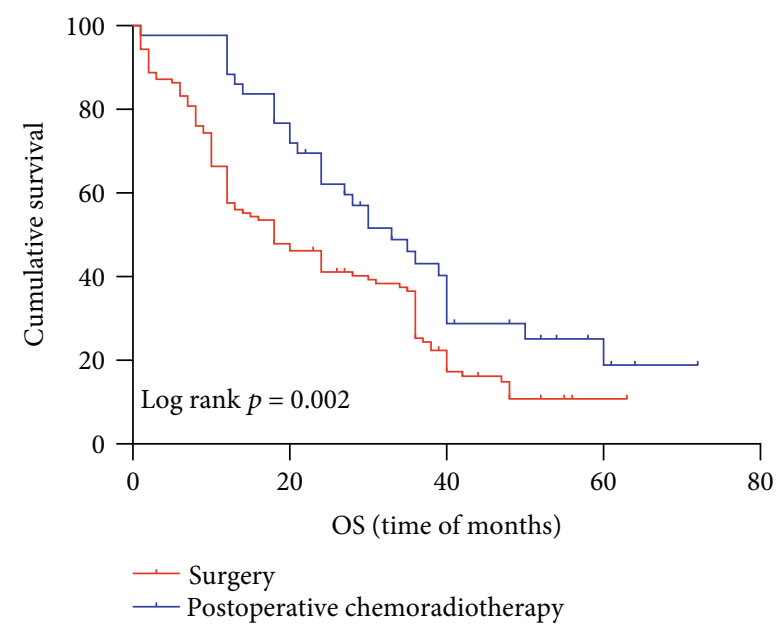

(d)

FIgURe 3: Kaplan-Meier curves for overall survival of ESCC with lymph node metastasis, vascular invasion, nerve invasion, and the treatment of surgery plus chemotherapy. (a) Patients with vascular invasion have a significantly shorter survival $(p=0.011)$; (b) patients with lymph node metastasis have a significantly shorter survival $(p=0.006)$; (c) patients with nerve invasion have a significantly shorter survival $(p=0.02)$; (d) patients who had postoperative chemoradiotherapy have a significantly longer survival $(p=0.002)$.

consistent with previous studies. Moreover, the expression of FGF2-mRNA in the cancer tissues was significantly higher than that in the adjacent tissues in RT-PCR test, which was consistent with the results of IHC. The high expression of FGF2 was related to the tumor size $(p=0.026)$, gender $(p=0.047)$, and lymph metastasis ( $p=0.007$ ), while the expression of FGF2 was not correlated with the race, age, tumor site, and pathological stage of ESCC cases and so on $(p>0.05)$. The expression of FGF2 is related to gender and may be related to the male-to-female ratio of patients. Therefore, it can be speculated that FGF2 may be a promoting effect on the tumor progression. After survival analysis, the prognosis of FGF2 positive was significantly worse. FGF2 expression is considered an independent prognostic factor affecting the progression-free survival $(p<0.001)$ ESCC patients by Cox multivariate regression analysis. These results suggest that FGF2 may be used as an independent prognostic indicator of progression-free survival in patients with esophageal squamous cell carcinoma.

FGFR3 germ line mutations cause fatal dysplasia, cartilage growth not congruent, and congenital disorders. FGFR3 somatic mutations or excessive FGFR3 protein expression can lead to the development of a variety of malignant tumors. FGFR3 excessive gene mutation and protein expression were first discovered in bladder tumor. Besides, FGFR3 overexpression was found in gastric cancer and liver cancer. Studies have shown that dysfunction in FGFR3 or mutations of FGFR3 are highly associated with multiple cancers, such as multiple myeloma, bladder cancer [31], breast cancer [32], and colorectal cancer [33]. The activation of the FGFR3 signaling pathway can promote tumor growth, metastasis, and drug resistance [34, 35]. Studies have shown that that FGFR3 expression promoted tumor cell proliferation immunohistochemical analysis of early esophageal squamous cell carcinoma [36]. In previous studies of esophageal cancer, 


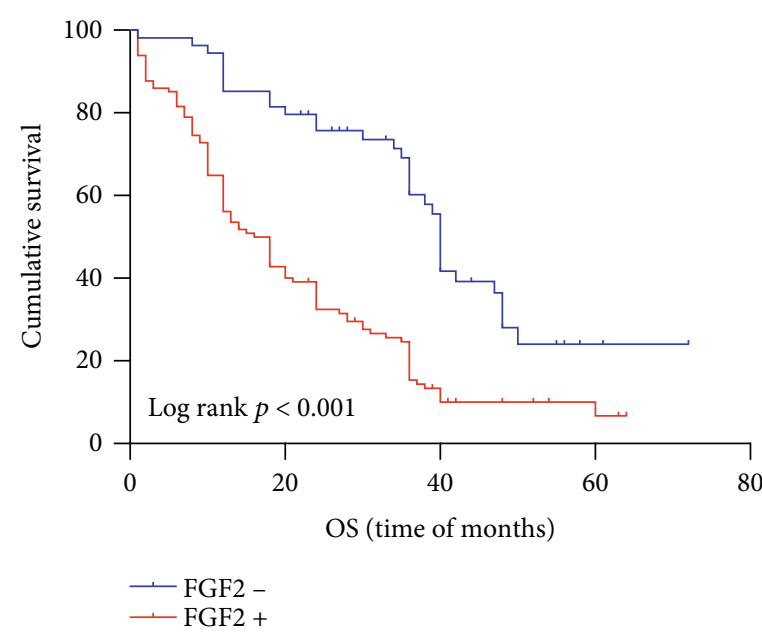

(a)

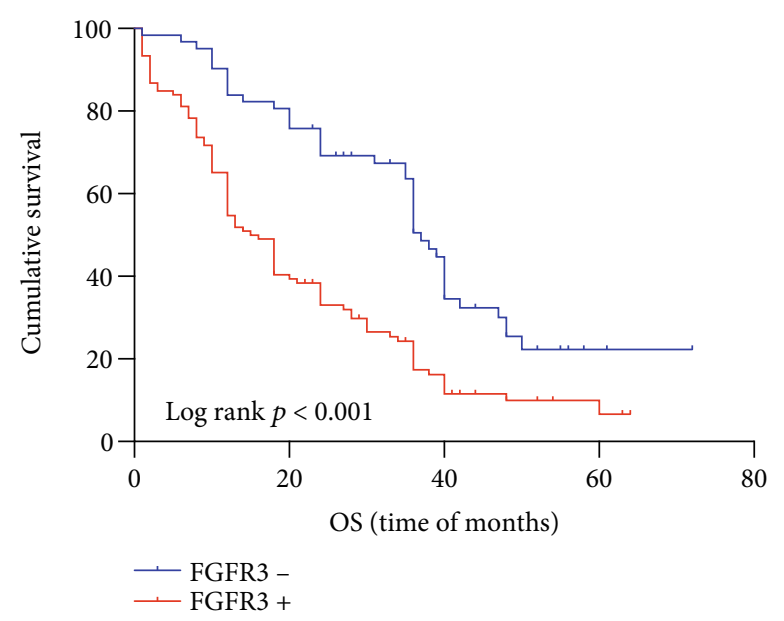

(b)

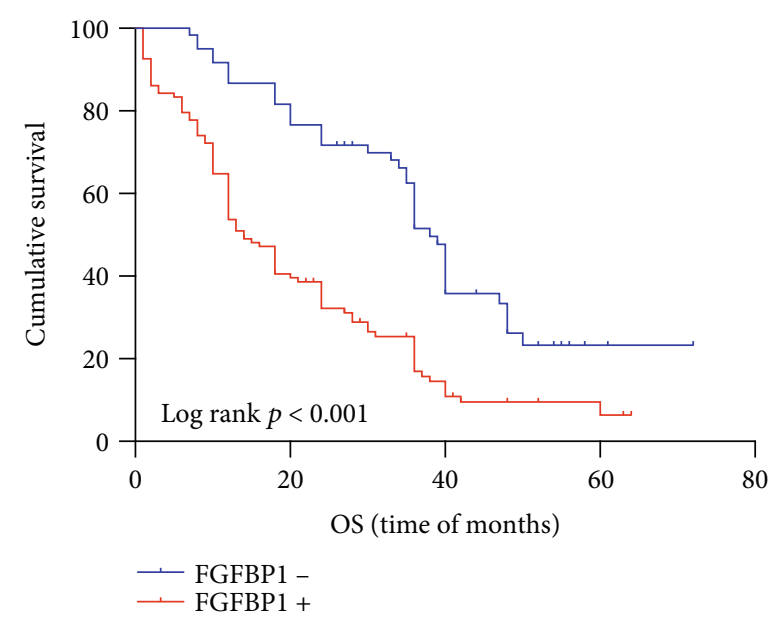

(c)

FIgURE 4: Kaplan-Meier curves for overall survival of ESCC with FGF2, FGFR3, and FGFBP1 expression. (a) Patients expressing high level of FGF2 have a significantly shorter survival $(p<0.001)$; (b) patients expressing high level of FGFR3 have a significantly shorter survival $(p<0.001)$; (c) patients expressing high level of FGFBP1 have a significantly shorter survival $(p<0.001)$.

FGFR3 was associated with tumor proliferation. In this study, the expression of FGFR3 in ESCC patients was significantly higher than that in tissues adjacent to carcinoma $(64.5 \%(111 / 172))$, which was consistent with FGFR3 expression in gastric and liver cancers in previous studies. And in RT-PCR, FGFR3-mRNA expression in cancer tissues was significantly higher than that in adjacent tissues $(p<0.001)$. Furthermore, the expression of FGFR3 in ESCC carcinoma was significantly higher than that in surrounding normal tissues. In this study, FGFR3 expression was associated with tumor differentiation $(p=0.043$ and $p<0.05)$, lymph node metastasis $(p=0.078$ and $p<0.1)$, and race $(p=0.033$ and $p<0.05)$, suggesting that FGFR3 may have an influence on the tumor development. FGFR3 expression is considered an independent prognostic factor affecting the overall survival $(p<0.001)$ and the progression-free survival $(p=0.003)$ in patients with ESCC by Cox multivariate regression analysis. The survival analysis showed that the FGFR3-positive patients had a poor prognosis. In this study, only advanced esophageal squamous cell carcinoma was selected, because of the greater influence of early and advanced cancers on the prognosis. The previous studies have suggested that FGFR3 may be of diagnostic value in early carcinoma, and further study of FGFR3 expression in early carcinoma of esophageal squamous cell carcinoma is warranted.

In the normal adult tissues, some studies have shown that FGFBP1 has also been shown to induce tumorigenic potential in epithelial cells [37] and to be highly expressed in oral cancer cell lines and tissues [38]. And other studies have found that overexpression of FGFBP1 can lead to skin diseases, such as psoriasis, actinic keratosis, and squamous cell carcinoma of the skin [39]. The previous studies have found that ed-71 (an anticancer agent for squamous cell carcinoma) inhibits tumor growth by inhibiting tumor angiogenesis in squamous cell carcinoma of the skin. One of the functions of ed-71 is to regulate the expression of HBp17/fgfbp- 1 in tumors, which can affect the release of fgf- 2 by ECM and 


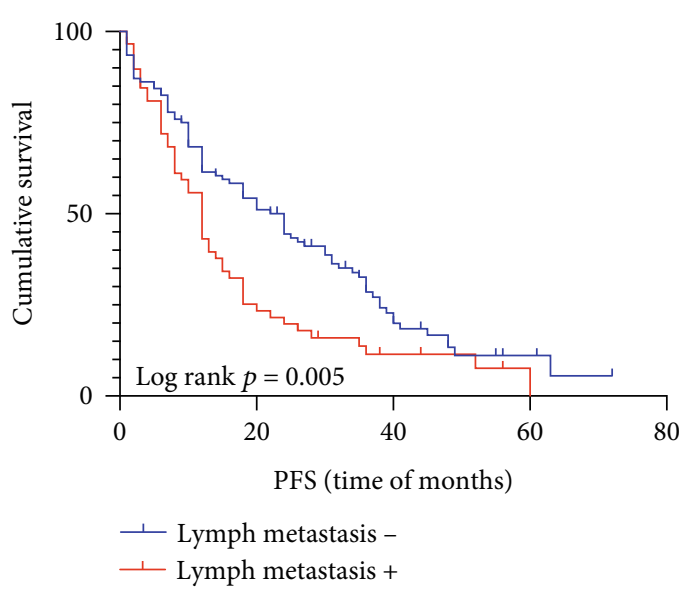

(a)

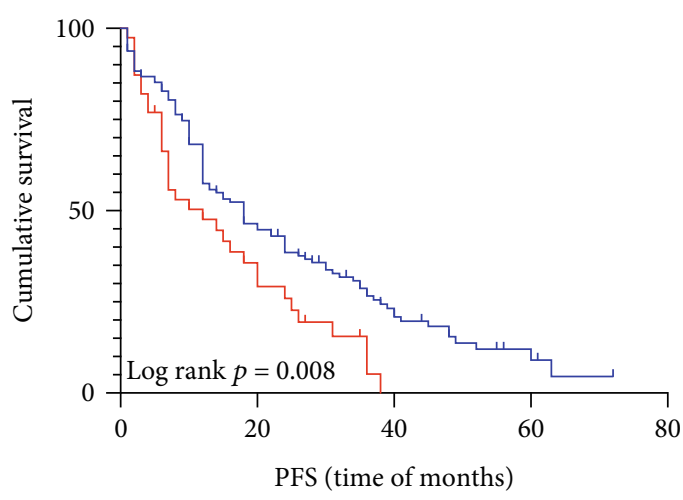

$\perp$ Distant metastases -

$\perp$ Distant metastases +

(c)

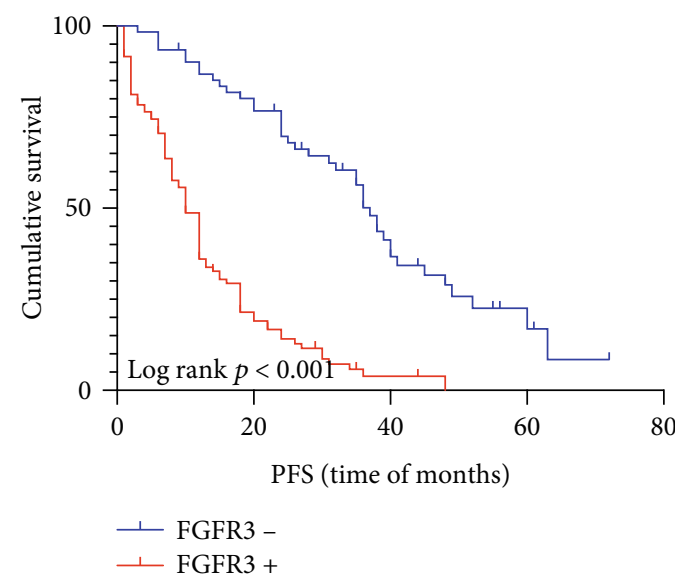

(e)

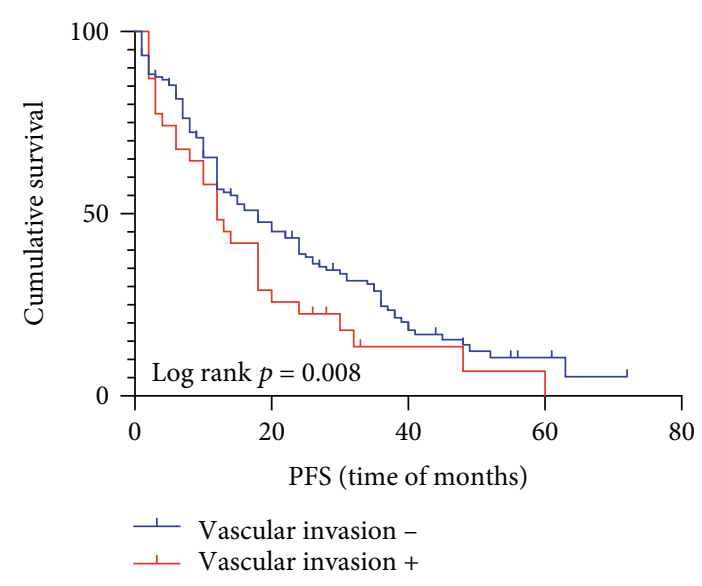

(b)

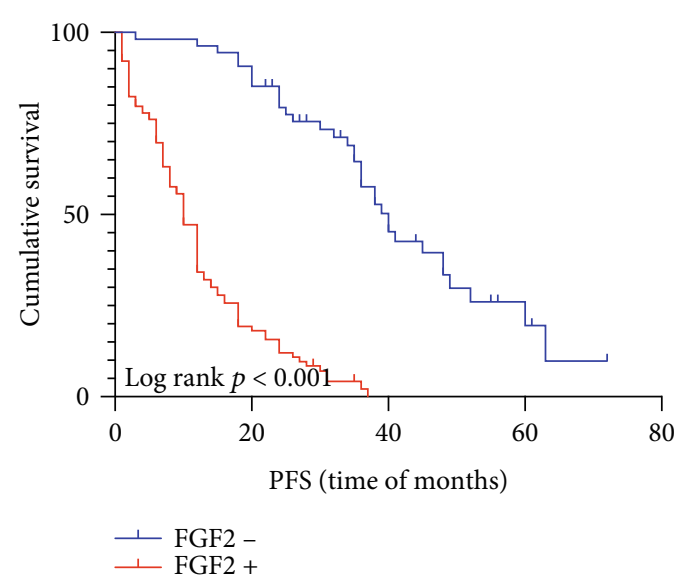

(d)

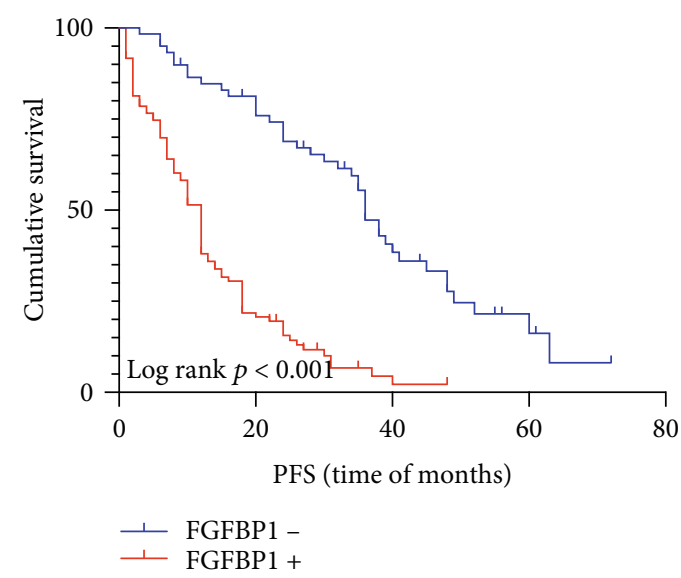

(f)

Figure 5: Kaplan-Meier curves for PFS of ESCC. (a) Patients with lymph node metastasis have a significantly shorter survival ( $p=0.005$ ); (b) patients with vascular invasion have a significantly shorter survival $(p=0.008)$; (c) the prognosis of patients with distant metastasis is poor $(p=0.008)$; (d) patients expressing high level of FGF2 have a significantly shorter survival $(p<0.001)$; (e) patients expressing high level of FGFR3 have a significantly shorter survival $(p<0.001)$; (f) patients expressing high level of FGFBP1 have a significantly shorter survival $(p<0.001)$.

angiogenesis [40, 41]. However, the expression in ESCC is unclear. The expression of this research shows that FGFBP1 from patients with esophageal is a high expression (70.2\%), thus making the results consistent with the expression of colon cancer, pancreatic cancer, and breast cancer. Moreover, RT-PCR further confirmed that the expression of FGFBP1 in ESCC tissues was higher than that in normal tissues $(p=0.001)$. The expression of FGFBP1 with ESCC 
TABLE 6: Univariable and multivariable analyses for overall survival and progression-free survival.

\begin{tabular}{|c|c|c|c|c|c|c|c|c|}
\hline \multirow{3}{*}{ Variable } & \multicolumn{4}{|c|}{ Overall survival } & \multicolumn{4}{|c|}{ Progression-free survival } \\
\hline & \multicolumn{2}{|c|}{ Univariable } & \multicolumn{2}{|c|}{ Multivariable } & \multicolumn{2}{|c|}{ Univariable } & \multicolumn{2}{|l|}{ Multivariable } \\
\hline & Median & $p$ value & HR (95\% CI) & $p$ value & Median & $p$ value & HR (95\% CI) & $p$ value \\
\hline \multicolumn{9}{|l|}{ Gender } \\
\hline Male & 24 & \multirow{2}{*}{0.286} & & & 15 & \multirow{2}{*}{0.127} & & \\
\hline Female & 36 & & & & 18 & & & \\
\hline \multicolumn{9}{|l|}{ Race } \\
\hline Han & 24 & \multirow{2}{*}{0.604} & & & 18 & \multirow{2}{*}{0.515} & & \\
\hline Kazakh & 24 & & & & 13 & & & \\
\hline \multicolumn{9}{|l|}{ Age (years) } \\
\hline$<65$ & 28 & \multirow{2}{*}{0.101} & & & 18 & \multirow{2}{*}{0.292} & & \\
\hline$\geq 65$ & 15 & & & & 12 & & & \\
\hline \multicolumn{9}{|l|}{ Tumor size } \\
\hline$<3 \mathrm{~cm}$ & 36 & \multirow{2}{*}{0.203} & & & 18 & \multirow{2}{*}{0.839} & & \\
\hline$\geq 3 \mathrm{~cm}$ & 20 & & & & 15 & & & \\
\hline \multicolumn{9}{|l|}{ Tumor site } \\
\hline Upper & 36 & \multirow{3}{*}{0.31} & & & 48 & & & \\
\hline Middle & 20 & & & & 12 & 0.178 & & \\
\hline Lower & 24 & & & & 18 & & & \\
\hline Differentiation & & & & & & & & \\
\hline Well & 30 & & & & 18 & & & \\
\hline Moderate & 21 & 0.422 & & & 14 & 0.158 & & \\
\hline Poor & 24 & & & & 20 & & & \\
\hline pTNM & & 0.065 & & & & 0.252 & & \\
\hline IB & 34 & & & & 36 & & & \\
\hline IIA.B & 24 & & & & 16 & & & \\
\hline IIIA.B,C & 20 & & & & 14 & & & \\
\hline Lymph metastasis & & & & & & & & \\
\hline Negative & 34 & 0006 & $0.75(0.51-1.09)$ & 0.131 & 24 & 0.005 & $0.912(0.631-1.319)$ & 0.626 \\
\hline Positive & 18 & 0.000 & (1) & 0.101 & 12 & & ) & 0.020 \\
\hline Vascular invasion & & & & & & & & \\
\hline Negative & 24 & 0.011 & $0.60(0.38-0.95)$ & 0.03 & 18 & 0.008 & $0.616(0.394-0.963)$ & 0.033 \\
\hline Positive & 14 & & & & 12 & & & \\
\hline Nerve invasion & & & & & & & & \\
\hline Negative & 24 & בח0 & $076(049-116)$ & 0204 & 15 & 0369 & & \\
\hline Positive & 14 & 0.02 & $0.70(0.49-1.10)$ & 0.204 & 16 & 0.00 & & \\
\hline Distant metastases & & & & & & & & \\
\hline Negative & 21 & 0.934 & & & 18 & 0.008 & $0.597(0.395-0.903)$ & 0.014 \\
\hline Positive & 24 & & & & 12 & & & \\
\hline Treatment & & & & & & & & \\
\hline Surgery & 15 & 0002 & $0.54(0.36-076)$ & 0001 & 13 & 0259 & & \\
\hline Postoperative chemoradiotherapy & 33 & 0.002 & $0.04(0.50-0.70)$ & 0.001 & 20 & 0.235 & & \\
\hline FGF2 & & & & & & & & \\
\hline Negative & 40 & $<0001$ & $057(032-101)$ & 0056 & 40 & $<0001$ & $0183(0.097-0364)$ & $<0001$ \\
\hline Positive & 16 & $<0.001$ & $0.3 /(0.52-1.01)$ & 0.050 & 10 & $<0.001$ & $0.105(0.097-0.504)$ & $<0.001$ \\
\hline FGFR3 & & & & & & & & \\
\hline Negative & 37 & $<0.001$ & $0.69(0.42-1.15)$ & 0.157 & 37 & $<0.001$ & $0.465(0.281-0.769)$ & 0.003 \\
\hline Positive & 15 & & & & 10 & & & \\
\hline
\end{tabular}


TABLe 6: Continued.

\begin{tabular}{|c|c|c|c|c|c|c|c|c|}
\hline \multirow{3}{*}{ Variable } & \multicolumn{4}{|c|}{ Overall survival } & \multicolumn{4}{|c|}{ Progression-free survival } \\
\hline & \multicolumn{2}{|c|}{ Univariable } & \multicolumn{2}{|c|}{ Multivariable } & \multicolumn{2}{|c|}{ Univariable } & \multicolumn{2}{|c|}{ Multivariable } \\
\hline & Median & $p$ value & HR (95\% CI) & $p$ value & Median & $p$ value & HR (95\% CI) & $p$ value \\
\hline \multicolumn{9}{|l|}{ FGFBP1 } \\
\hline Negative & 38 & \multirow{2}{*}{$<0.001$} & \multirow{2}{*}{$0.84(0.48-1.49)$} & \multirow{2}{*}{0.541} & 36 & \multirow{2}{*}{$<0.001$} & \multirow{2}{*}{$0.870(0.477-1.587)$} & \multirow{2}{*}{0.65} \\
\hline Positive & 14 & & & & 12 & & & \\
\hline
\end{tabular}

TABLE 7: Univariate analysis of overall and progression-free survival in patients with ESCC postoperative chemoradiotherapy.

\begin{tabular}{|c|c|c|c|c|c|c|c|}
\hline \multirow{2}{*}{ Variable } & & \multicolumn{3}{|c|}{ Overall survival } & \multicolumn{3}{|c|}{ Progression-free survival } \\
\hline & & Median & Log rank (chi-square) & $p$ & Median & Log rank (chi-square) & $p$ \\
\hline \multirow{2}{*}{ FGFR3 } & Negative & 40 & \multirow{2}{*}{3.691} & \multirow{2}{*}{0.05} & 36 & \multirow{2}{*}{12.154} & \multirow{2}{*}{$<0.001$} \\
\hline & Positive & 28 & & & 16 & & \\
\hline \multirow{2}{*}{ FGF2 } & Negative & 40 & \multirow{2}{*}{5.047} & \multirow{2}{*}{0.025} & 36 & \multirow{2}{*}{20.163} & \multirow{2}{*}{$<0.001$} \\
\hline & Positive & 27 & & & 16 & & \\
\hline \multirow{2}{*}{ FGFBP1 } & Negative & 40 & \multirow{2}{*}{7.901} & \multirow{2}{*}{0.005} & 36 & \multirow{2}{*}{20.403} & \multirow{2}{*}{$<0.001$} \\
\hline & Positive & 24 & & & 12 & & \\
\hline
\end{tabular}

cases of tumor differentiation $(p=0.012)$, age $(p=0.045)$, and lymph node metastasis $(p=0.032)$ has more obvious relationship, rather than gender, tumor size, tumor location, pathological stage, and vascular invasion of clinical pathology features. We can speculate that FGFBP1 may promote the development of esophageal squamous cell carcinoma through FGF2. Through survival analysis, there was a significant difference in survival time between FGFBP1-positive patients and negative patients. Patients with high expression of FGFBP1 had worse prognosis.

In the previous studies, the FGF/FGFR system is a key factor in tumor-microenvironment interactions [42, 43]. We found that fibroblast growth factor-binding protein (FGFBP1) was the carrier molecule of FGF2, which was first found in tumor cell lines [44]. Subsequent studies have shown that FGFBP1 binds to the FGF2 released from HSPG and then transports the bound FGF2 to the target cell surface $[45,46]$ to bind to FGFR. FGF/FGFR3 axis may induce carcinogenic effects by promoting cancer progression and increasing angiogenesis potential, leading to metastatic tumor phenotypes (Figure 7). Blocking one or more components of the FGFR signal pathway is being examined in preclinical studies and some clinical trials. However, early findings revealed that alterations in the FGFR gene do not occur uniformly across the various types/subtypes of cancer, suggesting the existence of complex interactions that vary between cancer types/subtypes $[47,48]$. The results of our study showed a positive correlation among these factors, suggesting that the FGF2-FGFR3 axis may play a certain role in promoting the occurrence of ESCC and affecting the prognosis of ESCC.

The studies have shown that FGF2 is frequently dysregulated in cancer, especially in advanced stages of dis- ease. The upregulation of FGF2 or FGFRs can promote resistance to chemotherapy. FGF2 is currently being evaluated in clinical studies as a potential predictive biomarker for hematological and solid tumors. FGF2/FGFR inhibitors are being developed and evaluated as monotherapy or as part of a combination therapy for the treatment of different types of cancer [49]. The finding was also found in our study that the survival times of patients with negative expression of FGF2, FGFR3, and FGFBP1 were significantly higher than that of patients with positive expression in 51 patients who received postoperative chemotherapy. It is concluded that the high expression of FGF2, FGFR3, and FGFBP1 in patients with ESCC may be prone to be resistant to chemotherapeutic drugs or radiotherapy. This is consistent with the relevant reports. Therefore, the inhibition of FGF2, FGFR3, and FGFBP1 may enhance the efficacy of chemotherapy, which is hopeful to make it an irreplaceable sensitizing target for cancer treatment. In this study, only immunohistochemistry and PCR were used. Further verification should be done by cell or animal tests.

In summary, the high expression of FGF2 was related to the tumor size of ESCC tissues and lymph node metastasis; the FGFR3 expression was associated with tumor differentiation, race, and lymph node metastasis. The expression of FGFBP1 with ESCC was associated with tumor differentiation degree, age, and lymph node metastasis. The protein and mRNA expressions of FGF2, FGFR3, and FGFBP1 were higher in the ESCC than in the adjacent tissues. FGF2, FGFBP1, and FGFR3 can promote the ESCC progression. FGF2 was significantly correlated with FGFR3 and FGFBP1, and FGFR3 was correlated with FGFBP1. The study further confirmed that the FGF2-FGFR3 axis may promote the progression of esophageal squamous cell 


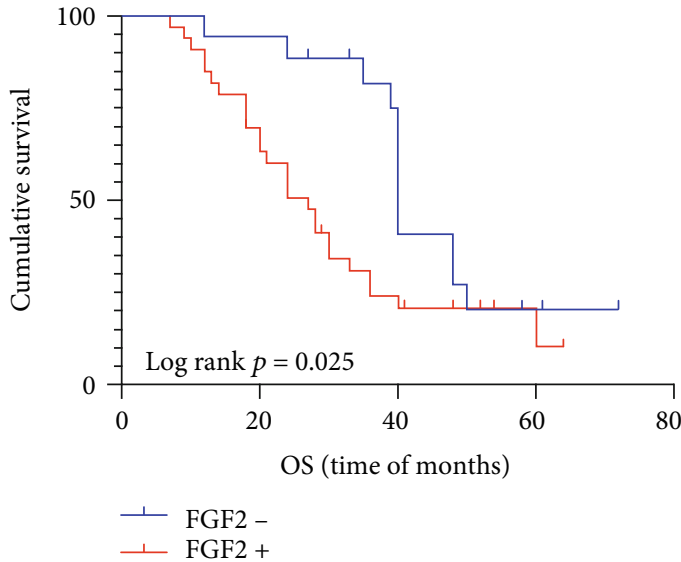

(a)

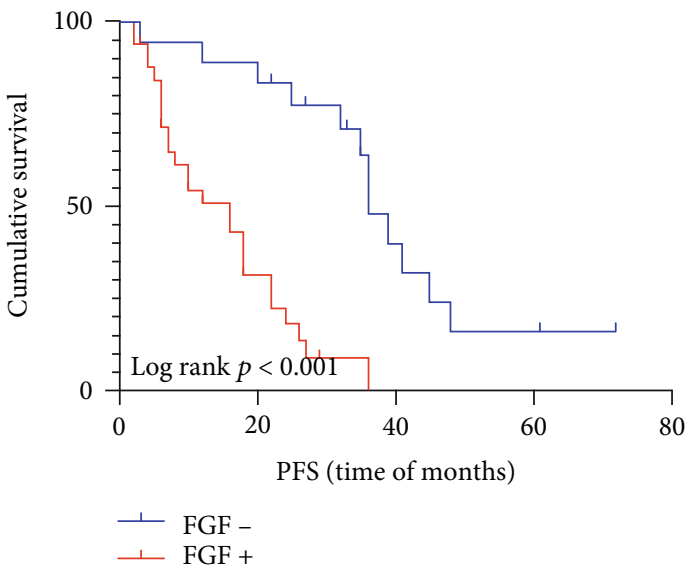

(c)

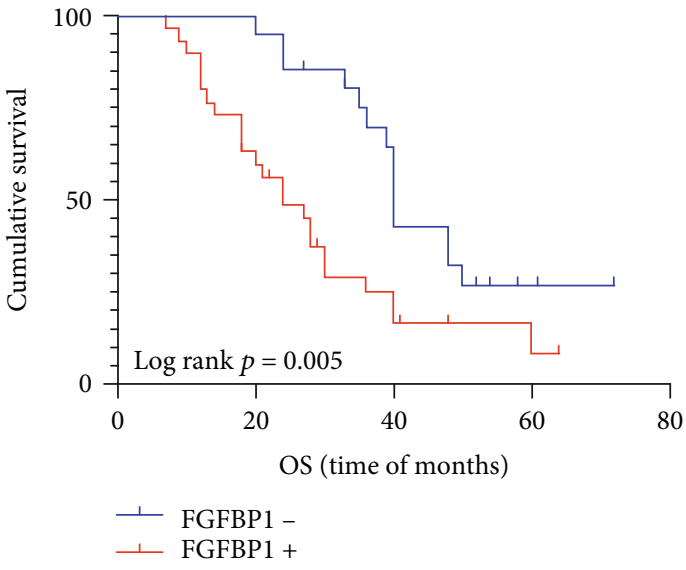

(b)

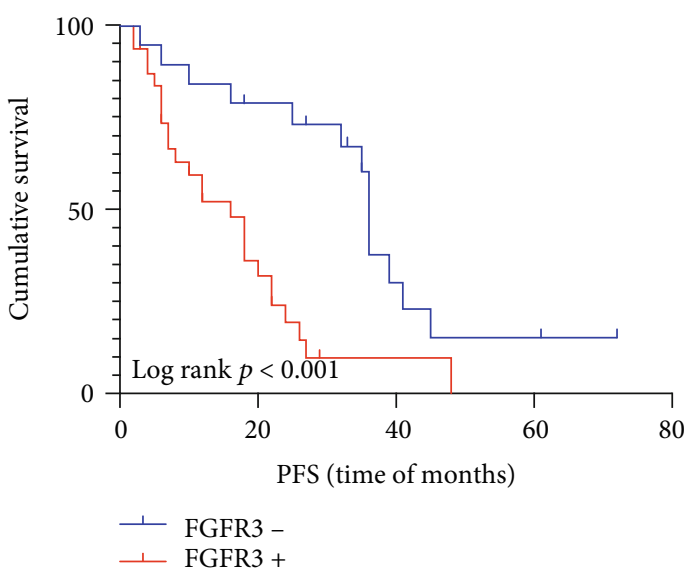

(d)

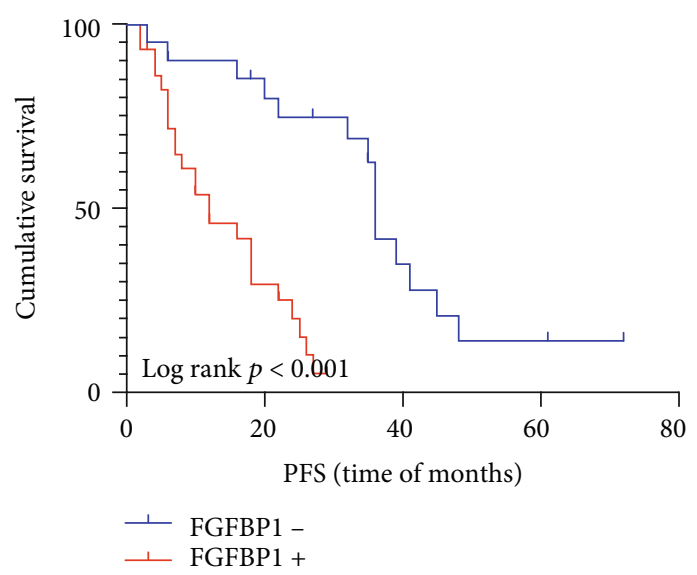

(e)

Figure 6: Kaplan-Meier survival analysis: total and progression-free survival in patients undergoing postoperative chemotherapy. (a) The OS of patients with FGF2 overexpression was shorter in ESCC $(p=0.025)$; (b) the high expression of FGFR3 had a poor OS in ESCC ( $p=0.05)$; (c) the high expression of FGFBP1 had a poor OS in ESCC $(p=0.005)$; (c) the PFS of patients with FGF2 overexpression was shorter in ESCC $(p<0.001)$; (e) the high expression of FGFR3 had a poor PFS in ESCC $(p<0.001)$; (f) the high expression of FGFBP1 had a poor PFS in ESCC $(p<0.001)$.

carcinoma. The FGF2-FGFR3 axis may be a new direction of targeted therapy for esophageal squamous cell carcinoma. Furthermore, high expression of FGF2, FGFR3, and FGFBP1 may increase drug resistance and reduce sur- vival. Therefore, blocking the FGF2-FGFR3 axis may inhibit the development of tumors. The inhibition of FGF2, FGFR3, and FGFBP1 may be further increased susceptibility to other chemotherapy drugs. The results of 


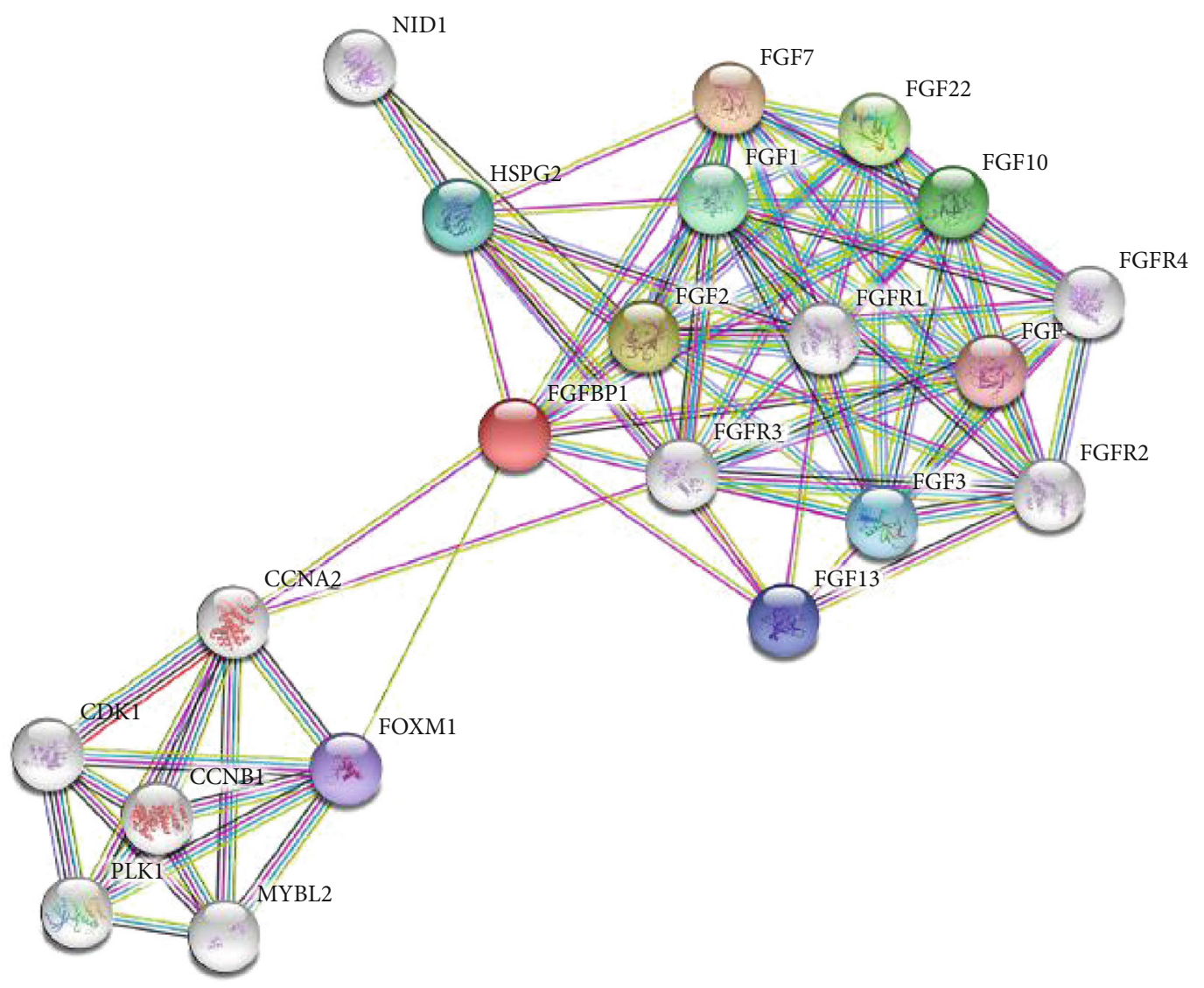

Figure 7: The connection diagram of FGF2, FGFR3, and FGFBP1.

multivariate analysis showed that both FGF2 and FGFR3 affected prognosis. Therefore, FGF2 and FGFR3 may be used as molecular markers for prognosis of ESCC.

\section{Data Availability}

The data of immunohistochemical and PCR used to support the findings of this study are included within the supplementary information file(s). The data used to support the findings of this study were supplied by Yuqing Ma under license. Because it involves patient privacy, so cannot be made freely available. Requests for access to these data should be made to Yuqing Ma (yuqingm0928@126.com).

\section{Ethical Approval}

This study was approved by the Ethics Committee of the First Affiliated Hospital of Xinjiang Medical University.

\section{Consent}

Signed written informed consent was obtained from all participants before the study.

\section{Conflicts of Interest}

The authors declare that they have no conflicts of interest.

\section{Authors' Contributions}

YQM, WJZ, and MYL designed the study and performed the experiments. WJZ, CL, YXZ, WYL, and SSX collected the data. And SSX and ZWJ analyzed the data. WJZ wrote the manuscript. All authors read and approved the final manuscript.

\section{Acknowledgments}

This study was supported by the grant from "The National Natural Science Foundation of China" (No. 81860422) and State Key Laboratory of Pathogenesis and Prevention of High Incidence in Central Asia jointly established by provincial and ministry (No. SKL-HIDCA-2020-4).Xinjiang Uygur Autonomous Region Natural Science Foundation For Youth Science Foundation Project (2018D01C182).

\section{Supplementary Materials}

Table 1(s)-Table 3(s): the data of immunohistochemical patients. Table $4 \mathrm{~s}-7 \mathrm{~s}$ : mPCR data information. (Supplementary materials)

\section{References}

[1] R. Siegel, D. Naishadham, and A. Jemal, "Cancer statistics, 2012," CA: a Cancer Journal for Clinicians, vol. 62, no. 1, pp. 10-29, 2012. 
[2] M. H. Taziki, S. Rajaee, N. Behnampour, M. Tadrisee, and A. R. Mansourian, "Esophageal cancer: 5-year survival rate at south-east of Caspian Sea of northern Iran," Journal of Cancer Research and Therapeutics, vol. 7, no. 2, pp. 135-137, 2011.

[3] W. Chen, R. Zheng, P. D. Baade et al., "Cancer statistics in China, 2015," CA: a Cancer Journal for Clinicians, vol. 66, no. 2, pp. 115-132, 2016.

[4] L. H. Moyes and J. J. Going, "Still waiting for predictive biomarkers in Barrett's oesophagus," Journal of Clinical Pathology, vol. 64, no. 9, pp. 742-750, 2011.

[5] F. Lordick, "Current standard and trends in oesophageal cancer," European Journal of Cancer, vol. 47, pp. S353S354, 2011.

[6] M. Korc and R. E. Friesel, "The role of fibroblast growth factors in tumor growth," Current Cancer Drug Targets, vol. 9, no. 5, pp. 639-651, 2009.

[7] A. Beenken and M. Mohammadi, "The FGF family: biology, pathophysiology and therapy," Nature Reviews. Drug Discovery, vol. 8, no. 3, pp. 235-253, 2009.

[8] O. A. Ibrahimi, F. Zhang, S. C. Lang Hrstka, M. Mohammadi, and R. J. Linhardt, "Kinetic Model for FGF, FGFR, and Proteoglycan Signal Transduction Complex Assembly†," Biochemistry, vol. 43, no. 16, pp. 4724-4730, 2004.

[9] P. J. Yu, G. Ferrari, A. C. Galloway, P. Mignatti, and G. Pintucci, "Basic fibroblast growth factor (FGF-2): the high molecular weight forms come of age," Journal of Cellular Biochemistry, vol. 100, no. 5, pp. 1100-1108, 2007.

[10] N. Itoh and D. M. Ornitz, "Fibroblast growth factors: from molecular evolution to roles in development, metabolism and disease," Journal of Biochemistry, vol. 149, no. 2, pp. 121130, 2011.

[11] O. Maehara, G. Suda, M. Natsuizaka et al., "Fibroblast growth factor-2-mediated FGFR/Erk signaling supports maintenance of cancer stem-like cells in esophageal squamous cell carcinoma," Carcinogenesis, vol. 38, no. 11, pp. 1073-1083, 2017.

[12] X. Zhang, O. A. Ibrahimi, S. K. Olsen, H. Umemori, M. Mohammadi, and D. M. Ornitz, "Receptor specificity of the fibroblast growth factor family. The complete mammalian FGF family," The Journal of Biological Chemistry, vol. 281, no. 23, pp. 15694-15700, 2006.

[13] C. J. Powers, S. W. McLeskey, and A. Wellstein, "Fibroblast growth factors, their receptors and signaling," EndocrineRelated Cancer, vol. 7, no. 3, pp. 165-197, 2000.

[14] J. J. Gómez-Román, P. Saenz, M. Molina et al., "Fibroblast growth factor receptor 3 is overexpressed in urinary tract carcinomas and modulates the neoplastic cell growth," Clinical Cancer Research, vol. 11, 2 Part 1, pp. 459-465, 2005.

[15] J. Qing, X. Du, Y. Chen et al., "Antibody-based targeting of FGFR3 in bladder carcinoma and t $(4 ; 14)$-positive multiple myeloma in mice," The Journal of Clinical Investigation, vol. 119, no. 5, pp. 1216-1229, 2009.

[16] E. M. Haugsten, A. Wiedlocha, S. Olsnes, and J. Wesche, "Roles of fibroblast growth factor receptors in carcinogenesis," Molecular Cancer Research, vol. 8, no. 11, pp. 1439-1452, 2010.

[17] G. Sonvilla, S. Allerstorfer, C. Heinzle et al., "Fibroblast growth factor receptor 3-IIIc mediates colorectal cancer growth and migration," British Journal of Cancer, vol. 102, no. 7, pp. 1145-1156, 2010.

[18] E. TASSI and A. WELLSTEIN, "The Angiogenic Switch Molecule, Secreted FGF-Binding Protein, an Indicator of Early
Stages of Pancreatic and Colorectal Adenocarcinoma," Seminars in Oncology, vol. 33, 6 Suppl 11, pp. 50-56, 2006.

[19] E. Tassi, K. McDonnell, K. A. Gibby et al., "Impact of Fibroblast Growth Factor-Binding Protein-1 Expression on Angiogenesis and Wound Healing," The American Journal of Pathology, vol. 179, no. 5, pp. 2220-2232, 2011.

[20] A. Kurtz, A. Aigner, R. H. Cabal-Manzano et al., "Differential regulation of a fibroblast growth factor-binding protein during skin carcinogenesis and wound healing," Neoplasia, vol. 6, no. 5, pp. 595-602, 2004.

[21] A. Kurtz, H.-L. Wang, N. Darwiche, V. Harris, and A. Wellstein, "Expression of a binding protein for FGF is associated with epithelial development and skin carcinogenesis," Oncogene, vol. 14, no. 22, pp. 2671-2681, 1997.

[22] D. M. Ornitz and N. Itoh, "The fibroblast growth factor signaling pathway," Wiley Interdisciplinary Reviews: Developmental Biology, vol. 4, no. 3, pp. 215-266, 2015.

[23] I. Ahmad, T. Iwata, and H. Y. Leung, "Mechanisms of FGFRmediated carcinogenesis," Biochimica et Biophysica Acta (BBA) - Molecular Cell Research, vol. 1823, no. 4, pp. 850860, 2012.

[24] S. Nayak, M. M. Goel, A. Makker et al., "Fibroblast growth factor (FGF-2) and its receptors FGFR-2 and FGFR-3 may be putative biomarkers of malignant transformation of potentially malignant oral lesions into oral squamous cell carcinoma," PLOS ONE, vol. 10, no. 10, p. e0138801, 2015.

[25] C. Basilico and D. Moscatelli, "The FGF family of growth factors and oncogenes," Advances in Cancer Research, vol. 59, pp. 115-165, 1992.

[26] E. Fessler, T. Borovski, and J. P. Medema, "Endothelial cells induce cancer stem cell features in differentiated glioblastoma cells via bFGF," Molecular Cancer, vol. 14, no. 1, 2015.

[27] T. Annese, R. Ronca, R. Tamma et al., "PTX3 Modulates Neovascularization and Immune Inflammatory Infiltrate in a Murine Model of Fibrosarcoma," International Journal of Molecular Sciences, vol. 20, no. 18, p. 4599, 2019.

[28] Y. Hu, Y. Qiu, E. Yagüe, W. Ji, J. Liu, and J. Zhang, “miRNA205 targets VEGFA and FGF2 and regulates resistance to chemotherapeutics in breast cancer," Cell Death \& Disease, vol. 7, no. 6, p. e2291, 2016.

[29] W. S. Brown, L. Tan, A. Smith, N. S. Gray, and M. K. Wendt, "Covalent targeting of fibroblast growth factor receptor inhibits metastatic breast cancer," Molecular Cancer Therapeutics, vol. 15, no. 9, pp. 2096-2106, 2016.

[30] N. Takase, Y.-i. Koma, N. Urakawa et al., "NCAM- and FGF2-mediated FGFR1 signaling in the tumor microenvironment of esophageal cancer regulates the survival and migration of tumor-associated macrophages and cancer cells," Cancer Letters, vol. 380, no. 1, pp. 47-58, 2016.

[31] S. Lott, M. Wang, S. Zhang et al., "FGFR3 and TP53 mutation analysis in inverted urothelial papilloma: incidence and etiological considerations," Modern Pathology, vol. 22, no. 5, pp. 627-632, 2009.

[32] S. Wang and Z. Ding, "Fibroblast growth factor receptors in breast cancer," Tumour Biology, vol. 39, no. 5, p. 1010428317698370, 2017.

[33] J. E. Fromme, K. Schmitz, A. Wachter et al., "FGFR3 mRNA overexpression defines a subset of oligometastatic colorectal cancers with worse prognosis," Oncotarget, vol. 9, no. 63, pp. 32204-32218, 2018. 
[34] M.-A. Natalia, G.-T. Alejandro, T.-V. J. Virginia, and L. M. Alvarez-Salas, "MARK1 is a Novel Target for miR-125a-5p: Implications for Cell Migration in Cervical Tumor Cells," MicroRNA, vol. 7, no. 1, pp. 54-61, 2018.

[35] S. Saichaemchan, W. Ariyawutyakorn, and M. Varella-Garcia, "Fibroblast growth factor receptors: from the oncogenic pathway to targeted therapy," Current Molecular Medicine, vol. 16, no. 1, pp. 40-62, 2016.

[36] N. Ueno, A. Shimizu, M. Kanai et al., "Enhanced Expression of Fibroblast Growth Factor Receptor 3 IIIc Promotes Human Esophageal Carcinoma Cell Proliferation," Journal of Histochemistry \& Cytochemistry, vol. 64, no. 1, pp. 7-17, 2015.

[37] X. Liu, S. Shi, J.-H. Chen et al., "Human fibroblast growth factor binding protein $\mathrm{HBp} 17$ enhances the tumorigenic potential of immortalized squamous epithelial cells," in Animal Cell Technology: Basic \& Applied Aspects, Springer, Dordrecht, 2002.

[38] S. Begum, Y. Zhang, T. Shintani, S. Toratani, J. D. Sato, and T. Okamoto, "Immunohistochemical expression of heparinbinding protein $17 /$ fibroblast growth factor-binding protein1 (HBp17/FGFBP-1) as an angiogenic factor in head and neck tumorigenesis," Oncology Reports, vol. 17, no. 3, pp. 591-596, 2007.

[39] M. O. Schmidt, K. A. Garman, Y. G. Lee et al., "The Role of Fibroblast Growth Factor-Binding Protein 1 in Skin Carcinogenesis and Inflammation," The Journal of Investigative Dermatology, vol. 138, no. 1, pp. 179-188, 2018.

[40] T. Shintani, S. N. Z. Rosli, F. Takatsu et al., "Eldecalcitol (ED71 ), an analog of $1 \alpha, 25$-dihydroxyvitamin D3 as a potential anti-cancer agent for oral squamous cell carcinomas," The Journal of Steroid Biochemistry and Molecular Biology, vol. 164, no. 11, pp. 79-84, 2016.

[41] T. Shintani, F. Takatsu, S. N. Z. Rosli et al., "Eldecalcitol (ED71 ), an analog of $1 \alpha, 25(\mathrm{OH}) 2 \mathrm{D} 3$, inhibits the growth of squamous cell carcinoma (SCC) cells in vitro and in vivo by downregulating expression of heparin-binding protein 17/fibroblast growth factor-binding protein-1 (HBp17/FGFBP-1) and FGF2," In Vitro Cellular \& Developmental Biology - Animal, vol. 53, no. 9, pp. 810-817, 2017.

[42] R. Ronca, A. Giacomini, M. Rusnati, and M. Presta, "The potential of fibroblast growth factor/fibroblast growth factor receptor signaling as a therapeutic target in tumor angiogenesis," Expert Opinion on Therapeutic Targets, vol. 19, no. 10, pp. 1361-1377, 2015.

[43] A. Giacomini, P. Chiodelli, S. Matarazzo, M. Rusnati, M. Presta, and R. Ronca, "Blocking the FGF/FGFR system as a "two-compartment" antiangiogenic/antitumor approach in cancer therapy," Pharmacological Research, vol. 107, pp. 172185, 2016.

[44] D. Q. Wu, M. K. Kan, G. H. Sato, T. Okamoto, and J. D. Sato, "Characterization and molecular cloning of a putative binding protein for heparin-binding growth factors," The Journal of Biological Chemistry, vol. 266, no. 25, pp. 1677816785, 1991.

[45] F. Czubayko, R. V. Smith, H. C. Chung, and A. Wellstein, "Tumor growth and angiogenesis induced by a secreted binding protein for fibroblast growth factors," The Journal of Biological Chemistry, vol. 269, no. 45, pp. 28243-28248, 1994.

[46] F. Czubayko, E. D. E. Liaudet-Coopman, A. Aigner, A. T. Tuveson, G. J. Berchem, and A. Wellstein, "A secreted FGFbinding protein can serve as the angiogenic switch in human cancer," Nature Medicine, vol. 3, pp. 1137-1140, 1997.
[47] Y. K. Chae, K. Ranganath, P. S. Hammerman et al., "Inhibition of the fibroblast growth factor receptor (FGFR) pathway: the current landscape and barriers to clinical application," Oncotarget, vol. 8, no. 9, pp. 16052-16074, 2017.

[48] I. S. Babina and N. C. Turner, "Advances and challenges in targeting FGFR signalling in cancer," Nature Reviews. Cancer, vol. 17, no. 5, pp. 318-332, 2017.

[49] M. R. Akl, P. Nagpal, N. M. Ayoub et al., "Molecular and clinical significance of fibroblast growth factor 2 (FGF2 /bFGF) in malignancies of solid and hematological cancers for personalized therapies," Oncotarget, vol. 7, no. 28, pp. 44735-44762, 2016. 